\title{
SAME-SEX MARRIAGE POLICIES AND LESBIAN FAMILY LIFE
}

\author{
by \\ Nikki DiGregorio
}

A dissertation submitted to the Faculty of the University of Delaware in partial fulfillment of the requirements for the degree of Doctor of Philosophy in Human Development and Family Studies

Summer 2014

\section{(C) 2014 Nikki DiGregorio}

All Rights Reserved 
All rights reserved

INFORMATION TO ALL USERS

The quality of this reproduction is dependent upon the quality of the copy submitted.

In the unlikely event that the author did not send a complete manuscript and there are missing pages, these will be noted. Also, if material had to be removed, a note will indicate the deletion.

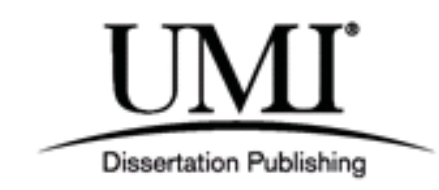

UMI 3642304

Published by ProQuest LLC (2014). Copyright in the Dissertation held by the Author.

Microform Edition (C) ProQuest LLC.

All rights reserved. This work is protected against unauthorized copying under Title 17, United States Code

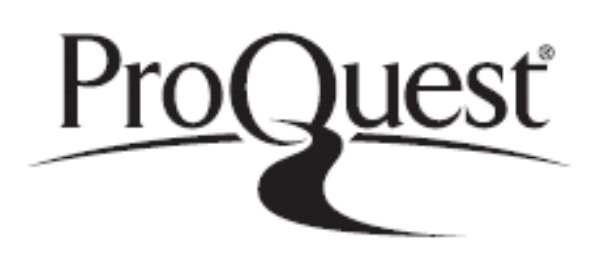

ProQuest LLC.

789 East Eisenhower Parkway

P.O. Box 1346

Ann Arbor, MI 48106 - 1346 


\title{
SAME-SEX MARRIAGE POLICIES AND LESBIAN FAMILY LIFE
}

\author{
by
}

Nikki DiGregorio

Approved:

Susan J. Hall, Ph.D.

Interim Chair of the Department of Human Development and Family Studies

Approved:

Lynn Reiko Okagaki, Ph.D.

Dean of the College of Education and Human Development

Approved:

James G. Richards, Ph.D.

Vice Provost for Graduate and Professional Education 
I certify that I have read this dissertation and that in my opinion it meets the academic and professional standard required by the University as a dissertation for the degree of Doctor of Philosophy.

Signed:

Bahira Sherif Trask, Ph.D.

Professor in charge of dissertation

I certify that I have read this dissertation and that in my opinion it meets the academic and professional standard required by the University as a dissertation for the degree of Doctor of Philosophy.

Signed:

Robin Palkovitz, Ph.D.

Member of dissertation committee

I certify that I have read this dissertation and that in my opinion it meets the academic and professional standard required by the University as a dissertation for the degree of Doctor of Philosophy.

Signed:

Barbara H. Settles, Ph.D.

Member of dissertation committee

I certify that I have read this dissertation and that in my opinion it meets the academic and professional standard required by the University as a dissertation for the degree of Doctor of Philosophy.

Signed:

Benjamin Fleury-Steiner, Ph.D.

Member of dissertation committee 


\section{ACKNOWLEDGMENTS}

I would like to express the deepest appreciation to Dr. Bahira Sherif Trask, whose continued support, encouragement, and guidance enabled me to complete this project. Thank you for teaching me how to educate others effectively; working with you has been an honor and one of the most rewarding experiences of my life.

This work would not have come to fruition without the assistance of Dr. Rob Palkovitz, Dr. Barbara Settles, and Dr. Benjamin Fleury-Steiner. The varied input stemming from a number of fields and concentrations has resulted in a truly interdisciplinary piece of scholarship, and for that I am very grateful.

I am especially grateful to have garnered the participants that made this project so exception. Their lived experiences give meaning and importance to the subject matter.

It is a pleasure to thank those who have supported me in other facets of my life. Thank you to my parents, Frank and Ann Marie, and my sisters, Celeste and Chrissy, for being patient with me throughout this process. I know I can be a difficult person. I would also like to express my gratitude to my friends and colleagues who shared their ideas and helped me keep going until I finished writing: Amanda Rich, Kelley Perkins, Caitlin Bailey, and Sarah Yarrusso. On the home front, thank you to Katherine Fallon for giving me the space I needed to focus all of my energy on this project; you truly are the bee's knees.

I would also like to thank SAGE Publications for permission to use a copyrighted figure, originally published in J.W. Creswell's (2007) Qualitative inquiry and research design: Choosing among five approaches" ( $2^{\text {nd }}$ ed.), p. 151.

Lastly, I want to acknowledge my animal companions, who sat beside me for countless hours as I wrote: Queso, Mumu, Hiccup, and Niko 


\section{TABLE OF CONTENTS}



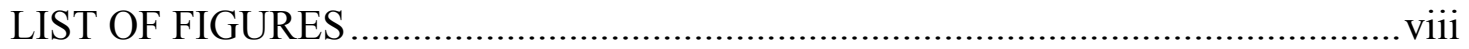



Chapter

1 INTRODUCTION ................................................................................... 1

The Legal Consciousness of Same-Sex Marriage................................................

Theoretical Framework ………………………………................................ 3

Feminist Standpoint Theory .............................................................. 4

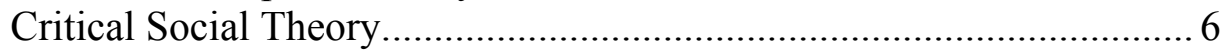

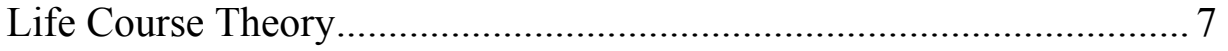

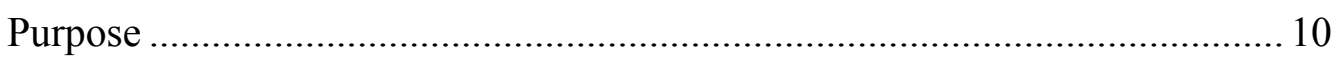

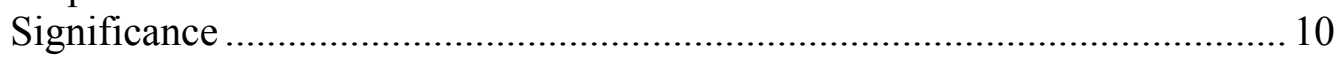

Research Questions …………………………………............................. 12



Historical Perspectives of Marriage ………………………….......................... 13

Social Change: 1960s to Present ................................................................. 14

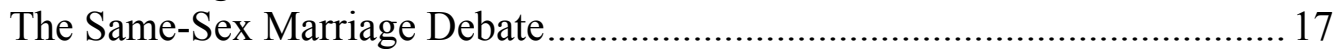



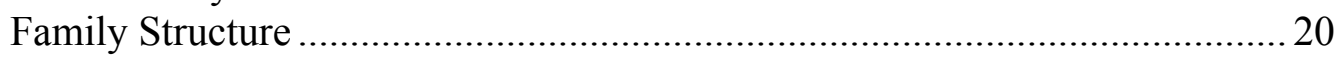

Lesbian Families.................................................................................... 26

Contemporary Research on Same-Sex Marriage .............................................. 28

3 RESEARCH DESIGN AND METHODOLOGY ………................................ 32

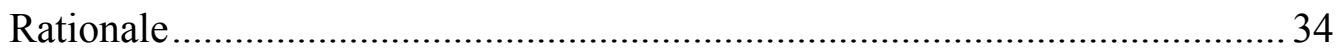

Foundations of Qualitative Inquiry ............................................................... 35

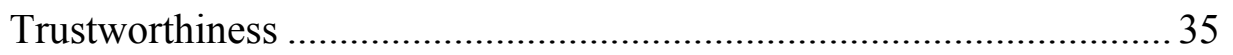

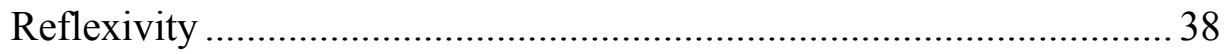




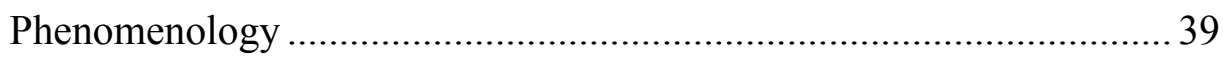

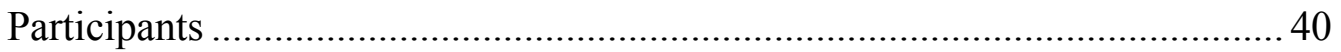

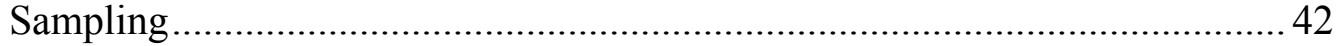

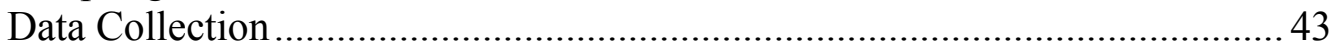

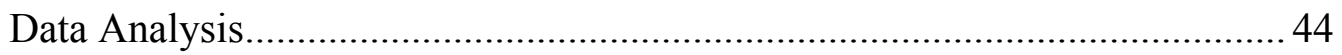

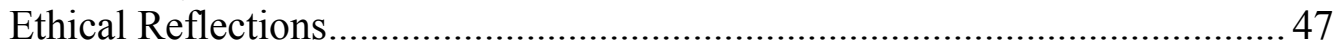





Marriage as a Civil Right ......................................................................... 56

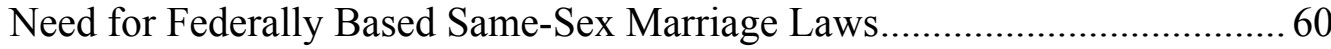

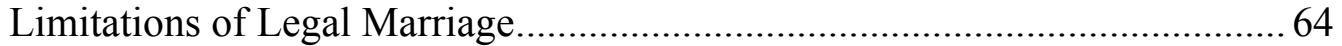

Dominant Concerns within the LGBTQ Community ..................................6 67

The Challenge of Guardianship for Lesbian Mothers .................................. 70

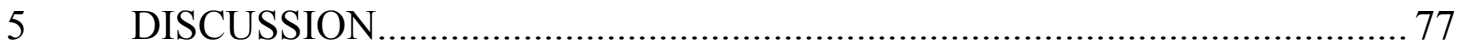

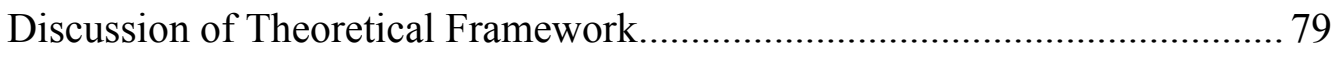



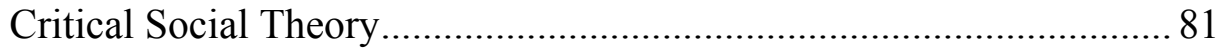

Life Course Theory ................................................................. 81

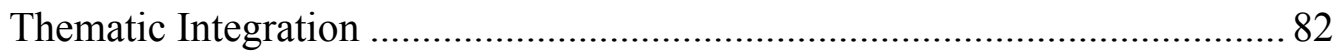

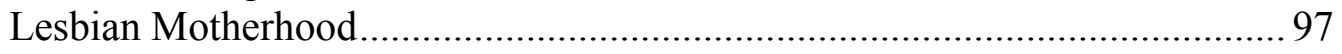

Limitations and Future Research............................................................. 100

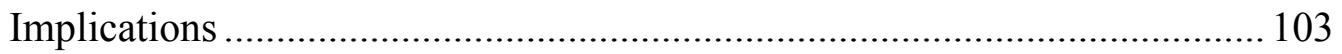

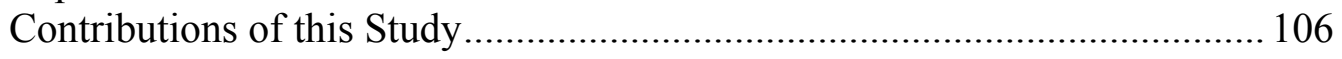

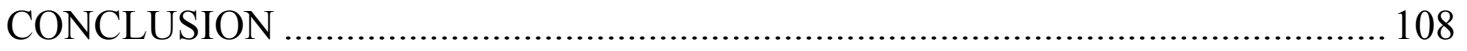

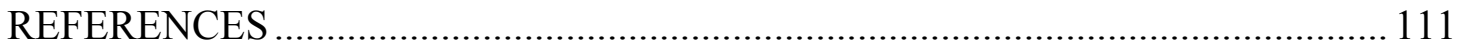

Appendix

A ORIGINAL SEMI-STRUCTURED INTERVIEW PROTOCOL ................. 125

B REFLEXIVE JOURNAL TEMPLATE ...................................................... 128

C INFORMED CONSENT AGREEMENT FOR PARTICIPANTS ...............129

D PERMISSION TO USE COPYRIGHTED FIGURE................................... 131

E UNIVERSITY OF DELAWARE IRB APPROVAL LETTER ..................... 133 


\section{LIST OF TABLES}

Table $1 \quad$ Participant Demographic Information............................................41 


\section{LIST OF FIGURES}

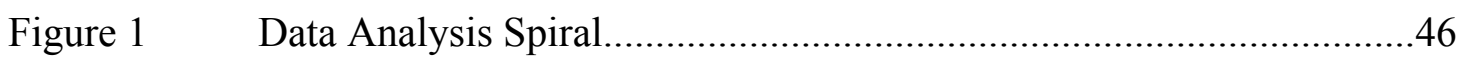




\begin{abstract}
This study investigates the relationship between marriage equality and its impact on parenting and committed monogamous relationships for lesbian women. Specifically, this study aimed to explore how marriage equality, or the lack there of, affects the daily lives of lesbian mothers and their children. As part of this study, the contours of the same-sex marriage debate are reviewed. Additionally, the debate itself is explored to help understand how it has taken shape both within and outside the GLBTQ community. Following this examination of the discourse surrounding samesex marriage, research on lesbian family dynamics is discussed. This line of research provides an important compliment to a focus on legal consciousness. Notably, how marriage equality or lack thereof matters in the lives of lesbian families necessarily includes attention to the da-to-day experiences in such families.
\end{abstract}




\section{Chapter 1}

\section{INTRODUCTION}

A substantial amount of social science research has explored the evolving nature of family life in the United States (Biblarz \& Stacey, 2010; Bumpass \& HsienHen, 2000; DeFrain \& Asay, 2007; Sweeney, 2002). Traditionally, the basic unit of a family has consisted of a man, a woman, and children (Parsons, 1951; Sweeney, 2002). However, in the recent past there has been considerable political and social debate regarding the rigidity of this conception of family (Burn, 2005; Patterson, 2000a, 2000b, 2005, 2009). This reconceptualization of family has helped to shape how researchers address same-sex families. Recently, academia has witnessed a growing body of research on same-sex families, but scholarship often does not specifically explore lesbian families. Nor does the majority of research investigate how marriage equality laws play a role in lesbian family perceptions. Operating from a feminist standpoint, as a lesbian woman, the researcher addresses this gap in academic literature as well as the gap in social policy.

\section{The Legal Consciousness of Same-Sex Marriage}

The omission of the issues surrounding same-sex marriage in the literature has become an increasingly critical area of interest over time. Obtaining same-sex marriage equality is a struggle for equal individual rights as much as it is a fight for equal family rights. Despite a growing body of literature that has begun to examine same-sex parenting, the majority of this research fails to do so within the context of 
legal consciousness (Ewick \& Silbey, 1998). The concept of legal consciousness refers to an individual's routine interaction with the legal system and the structural constraints that guide those interactions. Specifically, Ewick and Silbey (1998) illustrate three interrelated types of legal consciousness: before the law, with the law, and against the law. "Before the law" refers to the impartial, administrative nature of the legal system. People who see themselves as situated before the law view the legal system as an authoritarian force, outside of themselves, to which they must acquiesce (Ewick \& Silbey, 1998; Galanter, 2001). For example, same-sex couples that wish to marry but cannot legally do so are situated before the law. "With the law" concerns individuals who attempt to purposely interact with the law for their own benefit. Individuals positioning themselves with the law are using strategies to maneuver for the purpose of self-interest, and essentially move with the law. For example, an individual in a same-sex couple living in states wherein marriage is accessible that is trying to persuade their partner to marry is positioned with the law. Lastly, "against the law" pertains to the deliberate opposition to authority (Ewick \& Silbey, 1998; Galanter, 2001). Members of the LGBTQ community that are opposed to the fight for same-sex marriage equality, as well as to the participation in the institution of marriage, are positioned against the law (Goldberg \& Kuvalanka, 2012).

The majority of recent research does not address the legal consciousness of same-sex couples. Goldberg \& Kuvalanka's (2012) recent exploration of the legal consciousness (e.g., Ewick and Silbey 1998) of adolescents and young adults with lesbian, gay, and bisexual parents provides an excellent example of the variation in 
opinion regarding same-sex marriage. Drawing on a sample of 49 adolescents and emerging adults (ages 14-29), Goldberg \& Kuvalanka (2012) investigated the range of support and opposition for marriage equality among the children of lesbian, gay, and bisexual parents. More specifically, they sought to answer two questions: how this sample views marriage and marriage (in)equality, as well as how they think the lives of families like their own may be affected by marriage equality. Results indicated that, "more than $2 / 3$ of the participants conveyed unequivocal support for marriage equality" (Goldberg \& Kuvalanka, 2012, p. 41). This dissertation builds on this research by investigating the relationship between marriage equality and its impact on parenting for lesbian women. Specifically, this study explored how marriage equality, or the lack there of, affects the daily lives of lesbian families and their children. In the sections that follow, I begin by reviewing the contours of the same-sex marriage debate. Specifically, I explore how the debate has taken shape both within and outside the GLBTQ community. Next I attend to research on lesbian family dynamics. This line of research provides an important compliment to my focus on legal consciousness. Specifically, how marriage equality or lack thereof matters in the lives of lesbian families necessarily, including attention to the day-to-day experiences in such families.

\section{Theoretical Framework}

The theoretical frameworks employed in this study include feminist standpoint theory, critical social theory, and the life course perspective. These varied theoretical lenses provide the necessary groundwork for inquiry related to lesbian mothers as well 
as inquiry exploring social policy. Collectively, these frameworks permit the researcher to inquire about variances in experiences of lesbian families, couples, and women from differing parts of the United States; about the intersection of social policy and family processes within a socio-cultural-historical moment, and about the influence of these social policies on decisions made regarding legal status for the participants in this study.

\section{Feminist Standpoint theory}

The theoretical framework for this study is based on broadly based feminist theory which focuses on a critical analysis of existing dominant cultural ideologies, and seeks to provide explanations of social phenomena for the seekers, as individuals, as opposed to served establishments or institutions (Harding, 1986). Furthermore, several developmental theories focusing on women's life experiences can be useful in providing an explanation for the developmental paths of lesbian and heterosexual women. Specifically, Gilligan (1986) as well as Whitbourne and Powers (1994) have made contributions that provide unique lenses through which to view the female experience. Gilligan (1986) proposed that women and men communicate their responses to experiences differently when they are faced with ethical quandaries. Similarly, Whitbourne and Powers (2007) suggest a subjective model of women's psychological development that links women's identity to the psychological processes that one uses to adjust to life events and changes. Whitbourne and Powers (2007) posit that women's early life assumptions interact with current social and cultural expectations and develop into a lifespan construct. 
Additionally, standpoint theory (Harding, 1986) branched out of feminist thinking which is rooted in understanding different positions held by women in society. This theory states that the position of women, which is generally subordinate, ultimately affects their view of the world. Two important points proposed by this theoretical framework have particular relevance for this study, the need to hear the "voices" of people regardless of their race, class, sexuality, and gender, and increasing sensitivity to social positions within various societies (Adams \& Phillips, 2006).

Hartsock (1983) notes that not all women have the same experiences, thus, making it very unlikely for them to arrive at a common standpoint. However, she argues that women in Western societies, as a group, are pressured to become people who can produce goods and human beings (Hartsock, 1999). It is this level of cultural similarity that results in women sharing the same perspective to some extent. Although lesbian women come from various spheres of the population, they do share a common "domain" which influences their world view, their sense of self, and their satisfaction with their lives.

Harding (1991) argues that life is always experienced from multiple levels of meaning and each experience is imbedded in social ideology. As a result, women have to critically evaluate their positions in society, their social roles, as well as their intimate relationships. This task leaves women of all ages, but especially lesbian women, with a difficult undertaking. They are faced with the daunting task of evaluating themselves from the perspective of being female in a dominantly 
patriarchal society, being mothers raising children with other women, and identifying as lesbian in a dominantly heterosexual society.

It is through contributions of standpoint epistemology and reflective practice (Naples, 2003) that this study produces rich narratives that will highlight new, detailed angles of the everyday lives of this sample of lesbian mothers, in committed relationships, situated in varying environments of social policy at the state-level. Furthermore, the standpoint framework lends itself to understanding how the perspective of the researcher serves as a catalyst for the development of this research study. As a lesbian woman conducting research on the nuanced experiences of lesbian mothers, my vantage point provides insight into my intellectual pursuits as well as my personal history. My own experiences with relationships, social policy, legal consciousness, and family have shaped my understanding of each, along with having served as driving forces of social inquiry. This connection between standpoint and the researcher's goals on personal and academic levels is paramount to this study (Naples, 2003).

\section{Critical Social Theory}

Similar to standpoint perspective, critical theory has worked to counter the marginalization and stigmatization of subgroups within the population (Fay, 1987). Traditionally, critical theory has stressed the importance of questioning society, institutions, and cultural norms (Bernal, 1967; Fay, 1987). Extending this paradigm, critical social theory aims to evaluate pervasive inequalities via society and social institutions as well as perpetuate change (Freeman \& Vasconcelos, 2010). Fay (1987) 
proposed a fundamental schematic for applying the elements of critical social science including: a theory of crisis, a theory of education, and a theory of transformative action. The atmosphere surrounding same-sex marriage legislature is one of crisis, education, and transformative action as Fay (1987) states, "a theory of transformative action isolates those aspects of a society which must be altered if the social crisis is to be resolved and the dissatisfactions of its members lessened" (p. 32). Within the scope of this research study, the social crisis is understood to be one of access to equal rights via marriage law, and the transformative action(s) are changes in legislation in varying parts of the country. Moreover, this theoretical approach is applicable as it engages both participants and the researcher in reflective, critical evaluation of the interplay between far-reaching social, political, and economic systems and everyday life (Dante, 2003; Freeman \& Vasconcelos, 2010; Lather, 1986).

\section{Life Course Theory}

Lastly, life course theory is helpful in learning about families and transitions over time. More specifically, the life course perspective accentuates the timing and sequence of transitions (Elder, 1998; Hareven, 1987). Life course theory acknowledges that transitions have varying meaning depending upon when they occur during the life course and where they are situated with other sequential life events (Amato \& Kane, 2001; Elder, 1998; Hareven, 1987). Parenthood and marriage are examples of such transitions, and the timing of these events can be regarded as "on time" or "of time" depending on social and cultural norms. For lesbian mothers in the United States, legal marriage has only recently been viewed as a viable transition. 
Where this transition is situated within the life course for these women and their families has yet to be determined, along with whether or not this is a transition lesbian mothers choose to make. More specifically, the ways in which these transitions are similar and different for lesbian mothers juxtapose other kinds of mothers (e.g., single, heterosexual) has yet to be fully explored. Additionally, the overlap in experiences between cohabitating heterosexual couples and lesbian couples warrants further examination as cohabitation implicitly delays and/or negates the transition to marriage (Manning \& Cohen, 2012).

Additionally, life course theory is also helpful when examining variations in families (Bengtson \& Allen, 1993). Traditionally, the basic unit of a family has consisted of a man, a woman, and children (Parsons, 1951; Sweeney, 2002). However, in the recent past there has been considerable political and social debate regarding the rigidity of this conception of family (Burn, 2005; Patterson, 2000a, 2000b, 2005, 2009). The extent to which deviations from the life course family trajectory are accepted is predicated upon socially constructed norms to during a specific social, historic, and cultural moment (Elder, 1998; White \& Klein, 2002). More specifically, transitions that are made within the boundaries of social norms for a particular time period are referred to as normative transitions, whereas those that occur outside the parameters of social norms are deemed "non-normative" (Elder, 1998). These categorizations have a number of plausible implications for same-sex individuals, couples, and families. For example, transitioning non-normatively into a same-sex relationship or same-sex parenthood could result in a lack of familial and social 
support, as well as an absence of supportive legislature as is seen in the case of samesex marriage throughout the United States. Same-sex marriage, as well as lesbian motherhood, are both viewed as deviations from social norms. While in recent decades the United States has witnessed several important shifts in social acceptance of same-sex marriage and families, research has demonstrated that in many ways things have not changed in terms of daily living for lesbian mothers (Kurdek, 2004). For example, the lesbian mothers in this sample are still faced with the daunting task of navigating arenas wherein they are not afforded governmental supports to offset a lack of social acceptance. In states where same-sex marriage is not granted or even acknowledged, participants cited a lack of certainty when engaging with medical professionals or seeking out services in the public domain. In this regard, life course theory allowed the researcher and the participants to gain an understanding of how daily life is conceptualized within varying levels of legal consciousness, and how social policies or lack thereof, influences their lives. Interestingly, the range of ages among the participants in this study demonstrated the breadth of experiences within this sample. The life course framework permits researchers to examine both the individual and their families by giving attention to social context, historical moments, and dynamic processes (Elder, 1998; Hareven, 1987). Furthermore, life course approaches propose that family time and timing influence a number of facets of the lesbian lived experience, e.g., coming out, marriage, cohabiting, and childrearing. This perspective is particularly advantageous when investigating social phenomena 
such as same-sex marriage policy as it continues to emerge in varying parts of the country.

\section{Purpose}

The purpose of this study was to help bridge the gap in understanding how legal consciousness of lesbian parents and children in marriage equality/inequality states impacts perceived stigma/social acceptance as well as daily life. The aim was to build upon and expand the limited body of knowledge regarding how same-sex marriage legislature, or lack thereof, influences lesbian family life on both public and academic levels. Specifically, this study sought to examine the interplay between legal consciousness, social policy, and lesbian family life in their communities. Moreover, the rich narratives from this qualitative study lay the groundwork for deepening our understanding of the institution of marriage as it pertains to lesbian families for couples, families, children, service providers, community members, and policy-makers.

\section{Significance}

During the span of the last several decades the United States has witnessed a boom in same-sex marriage legislation. Simultaneously, these policy changes have been met with dueling opposition and support, varying by geographic location. In general, Americans are becoming more accepting of same-sex marriage but remain as opposed to homosexuality (Brewer, 2003; Brumbaugh et al., 2008; Lewis \& Gossett, 2008; Peplau \& Fingerhut, 2007). This movement towards support of same-sex marriage is indicative of the gay and lesbian movement moving with the law, 
insomuch as garnering support from both within and outside of the GLBTQ community (Ewick \& Silbey, 1998; Galanter, 2001). Historically, lesbian families have been absent from the overwhelming majority of family research. Recently, academia has begun to compensate for this omission. However, a comprehensive search of existing literature has demonstrated that significant gaps persist. Goldberg and Kuvalanka (2012) provided a research study investigating the perspectives of adolescents and young adults with lesbian, gay, and bisexual parents regarding samesex marriage. Building upon this research, this study addresses the issues as they pertain to lesbian mothers themselves, their families, their relationships, and their community.

Within the LGBTQ community discourse surrounding same-sex marriage fluctuates, varying in levels of support and opposition; however, these conversations have not fully translated into a deeper understanding both within academia or policy. As these changes continue in social policy continue to transpire, more and more lesbian women and their families will be entertaining the notion of legal marriage and what that means to them on multiple levels.

Addressing the relationship between access to marriage and lesbian families brings to light several complications. Foremost is the issue of accessibility, as even when social policy changes in favor of same-sex marriage equality, marriage is only attainable for a fragment of the lesbian population. Notably, because of the limited number of states where same-sex marriage is legal, but also because of other reasons such as economics. Secondly, many lesbian mothers do not wish to participate in the 
institution of marriage itself and feel there is a disjoint between their own ideologies and those values inherently part of marriage as it currently exists. Moreover, simply because marriage equality is attained legally on the state-level does not infer that these lesbian mothers and their families will experience the same level of validation and/or social support garnered by heterosexual married couples.

\section{Research Questions}

The gap that exists in understanding what these policy changes mean in terms of day to day functioning for lesbian mothers and their families is one that warrants attention. This exploratory qualitative study focuses on the following questions:

1) How does marriage equality/inequality affect the daily lives of lesbian families?

2) How are policy/social barriers in reference to same-sex marriage discussed across generations within lesbian families?

3) What perspectives do lesbian couples have on the impact of changing policy on their own relationships? In other words, does participation in, or rejection of, the institution of marriage change how they view their own families, their hopes/plans for the future?

The subsequent review of existing literature addresses issues related to the research inquiries of this study. 


\section{Chapter 2}

\section{REVIEW OF THE LITERATURE}

\section{Historical Perspectives of Marriage}

A great deal of the controversy that surrounds same-sex marriage has grown out of the fear that gay and lesbian families pose a threat to heterosexual family structures. However, researchers have noted that this kind of perceived threat to the dominant family structure has existed throughout the majority of American history (Carrington, 1999; Coontz, 1992). An overview of the history of marriage as well as its progression in contemporary American culture provides the necessary backdrop for understanding the current social, cultural, political, and historical atmosphere.

Historically, marriage within the parameters of American society served a predominantly practical purpose. Principally, unions were not about love; people married early and needed one another to survive physically. The transition from marriages founded upon practicality to marriages based on emotionality and compatibility is one that is relatively new (Coontz, 2005).

“Through most of human history, marriage united not just two mates but two sets of families" as Coontz noted (2005, p. 25).

The wide gamut of beliefs over the ages about how marriage should be organized and what its main purpose should be... So once we get past the seeming universality of marriage and examine the tremendous variations in the role it plays in different societies, it becomes much harder to define marriage and its reason for existence (Coontz, 2005, p.26)

By the middle of the 19th century marriage had come to be founded upon love and it was immoral to wed for any other reason (Coontz, 2005). Despite the transition 
to a sentimental version of marriage, and the new questions being asked, the same parameters that upheld the institution of marriage prevailed into the twentieth century. Coontz argues it was not until those parameters were pushed to their limits that a revolution of novel ideals about gender, love, and marriage would come to fruition (2005). Interestingly, what was actually going on in households during the $19^{\text {th }}$ century was different than what was prescribed by social norms. The number of households with parents or unmarried siblings increased before decreasing again in the

$20^{\text {th }}$ century, suggesting that even though people were exuding a focus on their spouse they still upheld the ideal of including members of birth families in their home (Coontz, 2005, p. 184).

\section{Social Change: 1960s to Present}

Throughout American history society has evolved via changes on micro and macro levels. Social change typically occurs slowly in waves, or rounds. Interestingly, this particular wave of the gay and lesbian movement has progressed exceptionally quickly. The first push for more freedom in terms of sexuality and its expression came on the wings of the civil rights movement, and is often referenced as the sexual revolution. This period of time would serve as a catalyst for a number of peripheral shifts as well. Shortly after, the gay and lesbian movement became more about rights as citizens, and it quickly became more of a family issue than an individualized one. Moreover, it is important to note that prior to the movement gaining momentum simply being identified as a gay or lesbian individual was enough to limit job security, career paths, and cause tension on interpersonal levels. The pace 
of the changes that have transpired in the United States surrounding same-sex relationships has been expeditious. This condensed timeline is atypical of social movements. For example, many individuals have witnessed the initiation and progression of this movement, even though they may only be in their 30 s or 40 s. The notion of a social movement being readily observed from conception to implementation implies that this is a fluid situation, and that there are day to day changes occurring. For many, being situated within a moment of social change and growth is worth acknowledgement. Life course theory (Elder, 1998; Hareven, 1987) posits that individuals move through life within historical, social, and cultural contexts. This framework provides an insight into the significance of the immediacy associated with the push for same-sex marriage, and informs researchers that age and community matter.

Throughout history we have seen a compartmentalization of social justice issues; e.g., race, class, gender, and more recently sexuality. Interestingly, same-sex relations are nothing new and have been observed throughout the history of mankind. The proliferation of the gay and lesbian movement has been accompanied by a loosening of sexual norms in many parts of the United States. This recent shift has suddenly made issues surrounding gay and lesbian sex less intimidating for academics and citizens alike. The implications of variations in sex include an understanding that not all sex was for procreation. At a time when studying sex was unheard of, Kinsey $(1948,1953)$ noted that approximately $4-12 \%$ of adults report engaging in same-sex activity, which is much higher than those who identify as gay or lesbian (NSSHB, 
2010). In contemporary American culture many aspects of sex are exploitative, and sex is more economically driven than it is by the sexual acts themselves. Research has demonstrated that sex can be analyzed as a marketplace wherein different resources are exchanged, however, which resources or sexualities are endowed is predicated upon social demand (Baumeister \& Vohs, 2004). More specifically, gay and lesbian sex has historically been ostracized, illegal, and socially sanctioned; making it an unlikely platform for the progression of social change. However, changes on multiple levels have propelled the movement forward at a remarkable pace, despite the stigmas attached to gay and lesbian sex.

Throughout history gays and lesbians have lived their lives under the radar of social norms. More specifically, large numbers of people were behaving entirely contrary to sexual norms and they were somewhat tolerated as long as they were very discrete, which is often referred to as the "norm of evasion" (Akers, 1985). The norm of evasion dictates that for roughly every social norm there is a countering norm of evasion that provides refuge from the reproach that result from its violation (Akers, 1985). For many members of the GLBTQ the recent shifts in acceptance and legal policies have created unprecedented levels of social freedom within the parameters of the norm of evasion. During the 1980s, sexual minorities began to garner support from factions of the population that were previously indifferent to the plight of GLBTQ individuals (Haas, 2002). In this regard, legality would then come to serve as a foundation for what is often referred to as social justice. 


\section{The Same-Sex Marriage Debate}

Discussions surrounding same-sex marriage both within and outside the GLBTQ community have been and continue to be sharply dichotomized (Clarke, 2003). That is to say, for a long time there has been an intra-GLBTQ community debate questioning whether or not marriage is an institution worth entering (Card, 1996; Rich, 1980; Clarke, 2003; Lewis \& Gossett, 2008; Hopkins, Sorensen, \& Taylor, 2013). Card (1996) argues:

Women who identify as lesbian or gay should be reluctant to put our activist energy into attaining legal equity with heterosexuals in marriage and motherhood, not because the existing discrimination against us is in any way justifiable, but because these institutions are so deeply flawed that they seem...unworthy of emulation and reproduction. (p.2)

Furthermore, adopting the patriarchal vocabulary that surrounds marriage and family, Clarke (2003) contends, could lead to same-sex marriage as a second-class institution. From this perspective, traditional, heterosexual marriage is viewed as oppressive and no longer supportive of a changing society that includes same-sex marriage (Card, 1996; Clarke, 2003; Josephson, 2005).

Current research suggests that gay and lesbian couples and families both challenge and reify heterosexual and gendered family forms (Hopkins et al., 2013). Many advocates within the gay and lesbian community would agree that same-sex marriage may complicate the possibility of marriage equality, as participation by same-sex couples in marriage would further confound the institution itself. However, proponents of same-sex marriage within the GLBTQ community assert that the primary purpose of the gay and lesbian movement has been to work for equal justice, 
including marriage equality. That is to say, same-sex marriage is sometimes viewed as a vehicle carrying the LGBTQ movement towards greater equality in a sense broader than simply access to marriage itself (Clarke, 2003). Indeed, another perspective highlights the possibility of lesbians and gays transforming traditional marriage into a more positive entity; something that is positive for themselves and less oppressive than traditional marriage (Clarke, 2003; Stoddard, 1997). Advocates posit that marriage between same-sex individuals will inherently transform the institution of marriage for everyone (Polikoff, 1993). By contrast, some scholars worry class privileged lesbians and gay men will be domesticated, and by participating in the institution of marriage they will reify a heteronormative order that ultimately cannot be inclusive (Brown, 2012; Duggan, 2002). Moreover, the only appeal to gays and lesbians for participating beyond legal status is that fulfilling social demands for normative order, in theory, could make life easier for marginalized populations in that choosing a non-normative lifestyle can have socially sanctioned repercussions.

The United States has witnessed a series of fragmented changes in opinions towards same-sex marriage over the past several decades, wherein the introduction of same-sex marriage legislature is often viewed as a result, not a cause, of shifts in public opinion. Furthermore, the current atmosphere surrounding same-sex marriage in the United States is an unprecedented one with support and opposition varying significantly by location and cultural groups. However, upon closer inspection it is evident that the divide within the United States runs deeper than state lines, and this divisiveness has served as a tipping point. Research has indicated that for the past 25 
years, in general, liberals, Democrats, and the less religious have become more accepting of same-sex relationships; while the majority of conservatives, Republicans, Protestants, and African-Americans have remained as opposed as they were in the past (Lewis \& Gossett, 2008; Olson, Cadge, \& Harrison, 2006; Sherkat, Powell-Williams, Maddox, \& De Vries, 2011). Despite these findings, there are certainly many individuals identifying as members of these communities that are more accepting. It is important to note that religious variables have a propensity to heavily influence the structure of attitudes about same-sex marriage (Olson et al., 2006). Where social policy intersects personal religious beliefs and norms is the focal point for much of the controversy that surrounds same-sex marriage.

\section{Social Policy and Families}

Policy researchers have long since noted that a number of family policies, including but not limited to, marriage, property distribution, divorce, and child welfare are determined on a state-by-state basis (Bogenschneider, 2006). This framework makes furthering our understanding of diverse family structures even more difficult as the parameters of these policies are generally not inclusive. For example, policy oriented texts rarely contain chapters or headings pertaining to child or family policy which is indicative of the individualistic as opposed to familistic nature of these writings (Bogenschneider, 2006; Huston, 1994). This divide is further exacerbated when we take into account same-sex couples with children. More specifically, if the policies in place are not able to fully support families headed by heterosexual couples 
they are even less apt to be able to provide the necessary supports for same-sex couples with children.

Additionally, within family policy interventions are situated within the parameters of aiding parents to do the best they can for their children, however, judgments and biases often play a role in the type and nature of support that is promoted (Gillies, 2005). Furthermore, the current disconnect across states regarding same-sex marriage policy forces same-sex couples to navigate new terrain. The role of interstate recognition of same-sex marriage licenses presents a unique problem for same-sex couples seeking divorce, exploring custody arrangements, or relocating. Bogenschneider (2006) proposes that perhaps the social policies we lack are more telling than those we uphold. This beckons for further exploration as research has demonstrated over time that families can more effectively support and promote themselves and their members when they can count on external support systems, e.g., social network, school system, communities, and an attentive government (Weissbourd, 1987; Hochschild, 1992; Bogenschneider, 2006).

\section{Family Structure}

“In policymaking...timing means everything” (Bogenschneider, p 9, 2006)

The structure and ecology of family has fluctuated so quickly that some assert government has not been able to keep up the pace (Bogenschneider, 2006). Interestingly, social norms have similarly lagged as the structure of families has changed faster than we as a society have been able to offer support. 
In the United States, policy influences public opinion, and the reverse is also true. Moreover, seeing as policies and laws are typically more reactive than proactive, it is important to take public opinion into consideration when considering the widely divergent paths states have taken in addressing the issue of same-sex marriage legislation. In regards to marriage, countless legal feuds have proved exemplary, varying by state and severity. Studies indicate that demographic characteristics can play a role in helping to predict attitudes of acceptance (Lewis \& Gossett, 2008; Olson et al., 2006). Research has also documented that the push-pull fashion of public opinion vacillates. The state of California provides an excellent example of social phenomena as research has demonstrated that shifts in public opinion are multifaceted. A study using six Field Polls of Californians spanning back to 1985 found that cohort replacement can account for half of the increase in support for same-sex marriage, while the other half is attributed to mind-changing or other factors (Lewis \& Gossett, 2008). Interestingly enough, the issue of same-sex marriage in politics is nothing new; in 1971 a Minnesota court was the first in the United States to decide a case on the issue. Seeing as same-sex marriage was perceived as unacceptable by the majority of heterosexual Americans in the very recent past, it was not until the Supreme Court of Hawaii case, Baehr v. Lewin/Miike 1993 (Somera, 1999) ruled that refusing same-sex couples the right to legally marry may have breached that state's laws against sex discrimination, that a national political response was prompted (Egan \& Sherrill, 2005; Haider-Markel, 2001; Lewis \& Gossett, 2008). Not surprisingly, this was followed by a span of policies and legal reforms geared towards promoting 
and supporting heterosexual marriage (Bogenschneider, 2000). More specifically, the American public responded with such fervent opposition that Congress passed the Defense of Marriage Act (DOMA), and over 36 states would follow suit in the years to follow (Cahill, 2004; Lewis \& Gossett, 2008). By 1996, thirty-six states had considered legislation banning same-sex marriage (Haider-Markel, 2001). Similarly, in 2003 when the high court of Massachusetts demanded that marriage licenses be issued to same-sex couples (Goodridge v. Department of Public Health, 2005), President G.W. Bush responded by advocating an amendment to the U.S. Constitution banning same-sex marriages, and 23 states complied by issuing state level bans (Lewis \& Gossett, 2008). Additionally, a study analyzing state-level same-sex marriage bans from 1973 to 2000 reported that for this particular policy change, supporters of samesex marriage bans proved to be more important in regards to legislative decisions than were non-supporters (Soule, 2004). However, like many controversial social policy issues, opponents of same-sex marriage bans have mobilized as well. Social movement theories that examine policies identify the significance of interest group activity, citizen ideology, as well as the general political opportunity (Burstein, 1991; Burstein \& Linton, 2002; Cress \& Snow, 2000; Giugni, McAdam \& Tilly, 1999). Research has shown that state policies usually reflect the beliefs and ideologies of the state's inhabitants, and as is readily apparent, these vary across states significantly (Clarke, Burns \& Burgoyne, 2008; Lewis, 2005). However, these beliefs are not impermeable to change, and it is widely agreed that social movements have some impact, whether it be direct or indirect (Cress \& Snow, 2000). Social movement 
theory illuminates the capacity of support social movement organizations to influence policy decisions at the local, state, and national levels (Andrews, 2001; Cress \& Snow, 2000).

Interestingly, in the United States the issue of same-sex marriage is often labeled as an issue of 'morality policy' (Haider-Markel, 2001; Koppelman, 1997; Soule, 2004; Williams, 2008). For many Americans, the concept of morality is central to their belief and value systems, and as a result 'morality issues' within politics tend to be prominent, non-technical, and have disproportional public support or opposition (Haider-Markel, 2001). While the majority of people in the United States view homosexuality as "morally" wrong, an increasing number are opposed to circumscribing the civil liberties of gay men and lesbian women (Brumbaugh, Sanchez, Nock, Wright, 2008; Loftus, 2001; Peplau \& Fingerhut, 2007). The general public is not the only tide shifting, as academics continue to tend to the gap-filled body of literature exploring gay and lesbian family life. Researchers have developed a psychometrically sound scale to assess support for same-sex marriage rights, and have employed this scale by pooling responses from 224 undergraduate students in New York (Brown \& Henriquez, 2011). An interesting relationship exists between attitudes towards homosexuality and support of civil rights for gays and lesbians. Americans are in fact becoming more supportive of civil rights for gays and lesbians; however, their attitudes regarding homosexuality continue to echo disapproval (Brewer, 2003; Peplau \& Fingerhut, 2007). Therefore, the way the public perceives homosexuality is not necessarily indicative of how they view civil rights for gays and lesbians (Brown 
\& Henriquez, 2011; Ellis, Kitzinger, \& Wilkinson, 2002). This distinction is important as it draws up the public and private dimensions of marriage, sex, and expression (Josephson, 2005). The atmosphere surrounding same-sex marriage across the United States meets the criteria of typical 'morality policy' issues, and is one that is met with fervent opposition and comparable levels of support, depending upon location.

Family policy has the capacity to both quietly and loudly wield power over how families operate. Bogenschneider (2006) demonstrates that in the United States policymaking is predominantly focused on individuals. Within this framework, policymakers cannot adequately see how lesbian families contribute to and are affected by social problems, as the individualistic approach of the majority of social policy operates from a heteronormative perspective. Understanding how lesbian families perceive and talk about policy changes provides a basis for expanding family research. To date, GLBTQ organizations and individuals, working with the law, have cogently utilized legislature and courts to progress their case for same-sex marriage (Brumbaugh et al., 2008; Edgwick \& Silbey, 1998). It is widely understood that families are not static, but dynamic, fluid entities that relate to varying cultures and histories (Bengston, 2001; Coontz, 2000; Smart \& Shipman, 2004). By refusing to recognize same-sex relationships as worthy of the equal privileges given via legal marriage is akin to saying that the relationships of gay men and lesbians are inherently less valid within society than heterosexual relationships. More specifically, marriage represents a status and is viewed as a marker of validation for relationships; insomuch 
as providing legal benefits to same-sex couples, legalization will also lay the foundation for granting same-sex couples the same social status as heterosexual couples. Marriage is often viewed as a prerequisite to the obtainment of certain rights and palpable benefits influencing how individuals are perceived by society and the government (Josephson, 2005). The same-sex marriage debate in the United States is, at its core, a disagreement regarding the nature of citizenship within this democracy and the meaning of full inclusion for citizens. Marriage has both private and public domains, and is touted as policymakers as being natural and unchanging (Josephson, 2005). An increased level of awareness of how unjust legislature are affecting families and couples within the United States may help to assuage some of the inequalities experienced by same-sex couples.

Alternatively, other scholars argue that granting the same benefits of marriage to the entire population for those who wish to participate would potentially help to ameliorate the stigma attached to lesbian relationships for lesbians themselves. Herdt and Kertzner (2006) argue that marriage denial negatively impacts the mental health of lesbians and gay men in the United States. A vast body of literature has ascertained that, in general, married heterosexual individuals have better mental health, lower rates of psychiatric disorder, and more emotional support; suggesting that marriage carries with it a host of benefits that extend well beyond legal rights (Gillis, 1999; Henry, Miller, \& Giarrusso, 2005; Lannutti, 2007; Lannutti, 2007a). More specifically, Ribar (2004) notes, "Marriage is positively associated with a large number of outcomes including improved cognitive, emotional and physical well-being 
for children, better mental and physical health for adults, and greater earnings and consumption for family members" (p. 4).

\section{Lesbian Families}

Historically, lesbian women have often contested heterosexual norms, i.e., the assumption that women are to marry a man, bear children, and become homemakers. It was not until after the 1980s that "coming out" as a lesbian did not inherently mean foregoing the possibility of having a child without prior conception with a man (Gartrell, Rodas, Deck, Peyser, \& Banks, 2006). In fact, in the past the term "lesbian mother" was often viewed as an oxymoron in itself (Hequembourg \& Farrell, 1999). Researchers argued that since lesbians cannot and do not have children on their own, they would likely be unable to parent effectively, as they are not biologically or psychologically apt to do so within a dyad consisting of two same-sex individuals (Kurdek, 2004). In general, contemporary research has resulted in a more realistic picture of lesbians raising children (Allen \& Demo, 1995). A study exploring family structure and family processes, more specifically family interaction processes such as touch, gestures, rules and decision making, found that consistent displays of affection and rule-making were a better predictor of family cohesiveness than family structure (Defrain \& Assay, 2007). Research has demonstrated that stable families have a penchant for raising strong, healthy children; regardless of the sexual orientation of the parent(s) or guardian(s) (Defrain \& Assay, 2007; Patterson 2005, 2009).

Current research focusing on lesbian women has demonstrated that lesbian parents are creating families in both traditional and novel ways by employing varying 
family structures composed of both kin and kith (Allen \& Demo, 1995; Perlesz, Brown, Lindsay, McNair, deVaus, \& Pitts, 2006; Weston, 1990). Historically, lesbian families have been excluded from the majority of family studies. Recent state-level policy shifts surrounding marriage equality have created an unprecedented opportunity for researching lesbian family life in the United States, creating a platform for research to better inform policy as it pertains to diverse family structures.

In the past, the primary moving force behind the majority of research done on gay and lesbian parents and their children came from judicial concerns about the psychological health and emotional stability of the children living in these families (Lambert, 2005). More recent research has indicated that there are more similarities than differences between lesbian and heterosexual mothers regarding how they value their children (Siegenthaler \& Bigner, 2000). Similarly, research on children who have been raised by lesbians has indicated that the children's psychosocial adjustment and development is effected more by family 'processes,' for example argumentativeness between parents, than it is by family structure in and of itself (Perlesz et al., 2006). Findings such as these are paramount in making the case for lesbian couples that wish to raise children within a family structure that is legally and socially supported via marriage. The possibility of lesbian motherhood is becoming more widespread and more widely acceptable in varying parts of the United States. Despite this development, lesbian families still face stigmas within our society. Goffman (1963) characterized stigmatization as the state of being denied complete social acceptance. Furthermore, stigmatization is not limited solely to the individuals 
that have the socially denounced attributes, but can extend to family members and friends as well (Goffman, 1963). A study exploring depression among lesbians found that it was directly related to a lack of sense of belonging to the general community (McLaren, 2009).

\section{Contemporary Research on Same-Sex Marriage}

A study exploring attitudes toward same-sex marriage within the context of worry regarding the weakening of heterosexual marriage found that, in general, women, Caucasians, and younger people are more approving of same-sex marriage than men, African-Americans, and older people (Brumbaugh, Sanchez, Nock, \& Wright, 2008). The study utilized data from a survey conducted in three states; Louisiana, Arizona, and Michigan. The researchers primarily interpreted their findings through a framework of vested interest in upholding the institution of marriage. Additionally, this study assessed the discomfort experienced by individuals with conflicting core values in terms of maintaining one's perceived sanctity of marriage juxtapose the notion restraint of individualism for others.

However, research on gay and lesbian couples have found a number of similarities exist alongside their heterosexual counterparts. More specifically, research has demonstrated that regardless of sexual orientation, the majority of individuals regard dependability, affection, shared interests, and similar religious beliefs as important within romantic relationships (Peplau \& Fingerhut, 2007). In this regard, lesbian couples can be viewed as similar to both cohabiting and married heterosexual couples. 
Throughout history marriage has represented both a public demonstration of commitment as well as a legal status for heterosexual couples (Peplau \& Fingerhut, 2007). An estimated 1,138 rights are afforded to married couples upon their union (Peplau \& Fingerhut, 2007). It is important to note that legislation that regards married individuals differently than single individuals pervades nearly every aspect of social regulation in the United States (Chambers, 1996). Laws surrounding taxation, social welfare, adoption, inheritance and a slew of others vary state by state and are included in having a legally valid marriage (Chambers, 1996). By contrast even if same-sex couples went forward and were to expend the time, energy, and money to secure all of the proper documents and legal services afforded by governmental acknowledgement of their union, i.e., marriage; they would still fall short of obtaining equal access to the rights afforded by legal marriage (Chambers, 1996; Josephson, 2005). For example, the Family and Medical Leave Act of 1993 does not extend itself to same-sex couples, regardless of the circumstance. Additionally, the pro-marriage nature of social policy in the United States can also be readily observed by the differing legal rights afforded heterosexual cohabiting couples and heterosexual married couples. This illustrates that legislation fails to support a number of varying family structures, including but not limited to lesbian families.

Lesbian couples typically raise children in the United States under three sets of circumstances: one of the partners already has biological children from a previous relationship, the couple conceives via reproductive assistive technology and raises a child together, or the couple adopts (Chambers, 1996). Similarly, heterosexual 
couples raise children in all of these ways as well, except when these couples marry they are treated differently. In 2010, the U.S. Census data indicated that there are currently slightly over 900,000 same-sex couples living together (Census, 2010). Interesting, in 2000 the census reported over 600,000 same-sex couples (Peplau \& Fingerhut, 2007). These statistics could imply that more people in the United States are willing to identify themselves with markers of sexuality, and as the U.S. Census itself strives to become more accessible to marginalized populations the results are becoming more reflective of families as they exist in our country. It is readily apparent that our understanding of how these families form, maintain themselves, where they strive, where they struggle, what supports they need, what supports they receive, and how they make decisions regarding legal status leaves much to be desired. This qualitative study sought to explore the experiences of lesbian mothers in varying parts of the United States to help inform communities, policy makers, and academics alike of the varying levels of legal consciousness and perceived policy support for this sample. The rich, detailed narratives produced by the participants provide a unique vantage point from which to view the institution of marriage, marriage accessibility, and plausible influences of marriage on lesbian relationships and parenting. Additionally, through exploration of these experiences researchers and participants alike are provided with new levels of understanding. More specifically, researchers and academics benefit from garnering novel information and data pertinent to the social phenomenon of inquiry, and participants are given an opportunity to engage with information and express themselves in a manner that allows their voices to be 
heard beyond the community level. Consequently, results of this study carry weight for policymakers. As a number of social changes continue to progress and LGBTQ community members become increasingly more visible within academic research, family structures continue to change as a result. Moreover, our definitions of what constitutes a family will continue to shift our understanding of how these families and individuals are influenced by social policy, and will become a more readily acknowledged topic of conversation for policymakers. 


\section{Chapter 3}

\section{RESEARCH DESIGN AND METHODOLOGY}

The purpose of this exploratory study was to lay the necessary groundwork for current and future investigation regarding accessibility to marriage and its implications for lesbian families. Additionally, this study sought to build upon the scarce amount of research on lesbian families with children in the United States as well as to better inform families, parents, policymakers, researchers, and community members of the varying experiences with marriage policy of lesbian mothers with children.

In seeking to better understand the issue of marriage within the lesbian community, this study aimed to address three major research questions:

1) How does marriage equality/inequality affect the daily lives of lesbian families?

2) How are policy/social barriers in reference to same-sex marriage discussed across generations within lesbian families?

3) What perspectives do lesbian couples have on the impact of changing policy on their own relationships? In other words, does participation in, or rejection of, the institution of marriage change how they view their own families, their hopes/plans for the future?

The nature of this study warranted a qualitative approach, as semi-structured in-depth interviews provide a wealth of knowledge and an exclusive vantage point for investigating the relationship between family policy and family life within this subgroup of the greater population (Flick, 2006). Previous research that has been 
conducted surrounding marriage equality and lesbian families guided the questions asked during the interview process (Jacob \& Furgerson, 2012). The purpose of utilizing this interview format was to garner rich data that will reflect both the larger influences of social policy on lesbian families and also capture the subtle, nuanced aspects of daily family life that are undermined or supported by marriage laws (See Appendix A for semi-structured interview protocol). The challenge for the researcher was to conduct interviews that elicited meaningful data while simultaneously ensuring that participants felt comfortable enough to share experiences (Knox \& Burkad, 2009). McNamara (2009) notes that the strength of employing an open-ended, semistructured interview approach is rooted in the researcher's ability to gather information from the same areas of interest with each participant. I believe this technique was most applicable to this study, as each participant was operating from a different standpoint and processed the questions differently, therefore, allowing flexibility in responses by leaving questions open-ended. This proved to be vital to the research process. More specifically, the interviews themselves were semi-structured, and increasingly interactive when warranted.

A number of prominent qualitative researchers advocate for analyzing data through a multiple stage process (Creswell, 2013; Edwards et al., 2002; Lincoln \& Guba, 1985). This same process was utilized for this study Interview transcriptions and field notes were analyzed for emergent themes and descriptive data. Upon beginning the coding process for the transcriptions, descriptions of the participants' lives and their understanding of the law as it pertains to them, were developed. 
Subsequently, as the participants' experiences with marriage legislature were explored, emergent themes became apparent. The feedback loop established between the researcher and the participant allowed for rich narratives to be acquired (Creswell, 2007; Flick, 2006; Given, 2008). Participant responses and their shared experiences resulted in emergent themes to be categorized.

\section{Rationale}

Qualitative research is frequently defined as a method of inquiry that is embarked upon by the researcher, operating as an apparatus for the collection of data, to allow for data to be collecting from multiple sources in a natural environment (Corbin \& Strauss, 2008; Creswell, 1998, 2010; Patton, 2005; Daly, 2007; Flick, 2006; Lincoln \& Guba, 1985; Strauss \& Corbin, 1998). This process allows for focus on the participants, and the meaning they allocate to the social phenomena of interest (Lincoln \& Guba, 1985; Strauss \& Corbin, 1998). Jaccard and Jacoby (2010) note that making sense of our reality is central to our lives; and that this reality is tied to a particular time and social context (p.7). Qualitative methodology allows the researcher to probe social phenomena through a process of understanding founded upon established practices (Creswell, 1998). This study warranted use of qualitative methodology as this specific topic has yet to be addressed with lesbian women, with children, in relationships living in varying states across the country, and this approach allowed the researcher to acquire detailed and rich accounts of the experiences of each participant. Furthermore, not only does this social issue necessitate exploration based solely on its absence in the literature; it requires attentive research, as it is one that is 
currently in flux and impacting the lives of many families. Additionally, the essence of the research questions is rooted in understanding how participants think about their experiences, in contrast to searching for relationships between variables; thus, providing support for the use of qualitative methodology (Creswell, 1998).

\section{Foundations of Qualitative Inquiry}

In congruence with Lincoln and Guba's (1985) work affirming the lack of certainty within qualitative inquiry this study adopted an emergent design. By doing so meaning was derived in context, and the information garnered during the interviews was predicated upon the interactions between the participants and the researcher. Additionally, traditions within qualitative methodology were employed, more specifically: trustworthiness, reflexivity, and phenomenology (Agar, 1986; Creswell, 1998; Daly, 2007; Nadin \& Cassell, 2006; Lincoln \& Guba, 1985; Schmid, 1981).

\section{Trustworthiness}

Schmid (1981) outlines qualitative research as being the investigation of the empirical world from the perspective of the person(s) being studied. Within this framework it is understood that behavior is shaped by the social, cultural, physical, and psychological environments. Furthermore, behavior is understood as being more than simply what is observed by the researcher (Krefting, 1991). Given the multiple qualitative approaches available, ensuring trustworthiness is a vital component to this research.

Often times, qualitative research is assessed utilizing criteria that were designed to evaluate quantitative research. Agar (1986) contends terms such as 
validity and reliability are erroneous in regard to qualitative work. For example, external validity refers to the extent one can generalize findings from their sample to the population, however, this is irrelevant in terms of qualitative research which aims to generate hypotheses (Krefting, 1991). For this study, generalization to the greater population was not an end goal other than to deepen an understanding of what marriage is, what it carries with it symbolically, legally, and how this influences the lives of these lesbian families.

Moreover, Agar (1986) proposed that different vernacular is necessary to assess the trustworthiness of qualitative work, including credibility, accuracy of representation, and authority of the writer. Guba's (1981) model of trustworthiness of qualitative research is founded upon four features that are pertinent to both qualitative and quantitative work: truth value, applicability, consistency and neutrality. Truth value questions whether or not the researcher has ascertained confidence in the truth of the findings regarding the subjects and the context, in other words, how confident the researcher is with the truth in the findings in terms of the research design, participants, and context (Lincoln \& Guba, 1985). Frequently truth is evaluated by how well threats to internal validity of the study have been addressed (Campbell \& Stanley, 1966). A primary threat to internal validity within qualitative research is data collector bias, which concerns the unconscious distortion of data (Denzin, 1978). The reflective field journal was maintained (See Appendix B for Reflective Journal Template), as well as candidness between the researcher and participants regarding personal biases and beliefs, in order to guard against this issue. 
Secondly, applicability refers to the extent to which the study's results can be implemented in other contexts and/or with other groups (Guba, 1981; Krefting, 1991). With that said, the results and structure of this study allow for expansive future work including longitudinal, comparative, social policy and advocacy research; and while they may not be directly applicable to other groups, the study provides a fundamental understanding of the daily lives of participating lesbian families and offers insights that will guide academics, community members, and policymakers alike. Furthermore, one of the strengths of qualitative work is that it is carried out in naturalistic settings with limited controlling variables, making each attempt unique and as a result, does not lend itself to generalizability (Krefting, 1991). Consequently, the purpose of this study was to describe the social phenomena and experiences of the participants, not to broadly apply them to others (Sandelowski, 1986).

The third canon of trustworthiness as proposed by Guba (1981) is consistency, or dependability. Since considerable variability is anticipated within qualitative research, consistency refers to the ability to explain sources of variability in the data, whether they be attributed to the researchers, participant, changing life situations, etc. Lastly, the fourth benchmark of trustworthiness is neutrality, or the level of independence from bias of the research processes and results (Guba, 1981; Sandelowski, 1986). Here, neutrality does not refer to objectivity, but more so ensuring that the voice of the participants is the loudest, clearest voice heard. Additionally, a colleague reviewed the data and reconvened with the primary 
investigator to discuss similarities and differences in our discoveries.

\section{Reflexivity}

Reflexivity involves contemplating the way in which the researcher is immersed in the research process, and how this immersion potentially influences the results (Nadin \& Cassell, 2006). Within qualitative research, reflexive approaches to research have become widely acknowledged (Ortlipp, 2008). Reflexivity also includes the estimation of influence of the researcher's background, perspective, and interests on the study itself (Agar, 1986; Creswell \& Miller, 2000; Shenton, 2004). Agar (1986) notes that the investigator's background determines the framework from which he or she conduct the research and analyze its results. Furthermore, both the participants and the researcher are stakeholders in this study, and reflexivity is imperative (Freeman \& Vasconcelos, 2010). Researcher reflexivity refers to selfdisclosure of assumptions, beliefs and biases on the part of the investigator; via this process researcher's account for how these biases may guide their research and interpretation of the data (Creswell \& Miller, 2000). As a researcher that is open about my sexuality, and having been an out lesbian for over a decade, my being pensive and deliberate about my own knowledge and experiences was imperative to this study. Homfray (2008) advocates for the use of gay and lesbian standpoints within qualitative research noting,

A standpoint exists to the extent that someone doing the same research who was neither lesbian or gay would have produced a significantly different piece of work, and, indeed may have experienced considerable resistance to participation should the respondents have been informed that they did not identify as either gay or lesbian (p.2). 
Similarly, attention was given to the dynamic nature of gender and sexuality, and the interplay between in-group and out-group status (Naples, 2003). All of the participants in this study identified as lesbian women, but they also identified as mothers. As a researcher that exists both within and outside of the GLBTQ community, my openness about my own sexuality granted me privilege within the domain of participant interviews. More specifically, through the interview process it became evident that a level of empathy developed in multidirectional fashion between the researcher and participants, which served to facilitate the research in a number of cases. However, as a lesbian woman without children, I maintained an outsider status in that regard. As I brought with me a host of biases, beliefs, and desires regarding marriage equality and parenthood that are relevant on both an academic and personal level, records of notes from interviews and reflective journal entries were kept to document findings as they emerged.

Additionally, the ability of the researcher to acknowledge their experiences as the research progresses is vital to ensuring that the data are reflective of the participants input (Homfray, 2008; Krefting, 1991). In an effort to improve society through research and knowledge, participants were given an opportunity to clarify information after interviews were conducted (Mabry, 2010).

\section{Phenomenology}

Ethnographic work provides valuable description, analysis, and interpretation of themes identified after engaging with participants in their preferred setting. This study focused on understanding the phenomenological experiences of the participants 
within the socio-cultural-historical moment of shifting same-sex marriage policies. The goal of a phenomenological study is to examine the experiences of participants in relation to the phenomenon of interest and to ascertain how they make meaning of these experiences.

\section{Participants}

A sample of 21 lesbian women ( 9 couples with children, 1 couple trying to conceive a child, and 1 reference point interview with a divorced lesbian mother) in self-defined long-term relationships (minimum of 1 year duration) were interviewed for this study. Lesbian couples living in the states that allow same sex marriage compared to lesbian couples living in neighboring states that do not grant same sex marriage licensure provided a unique platform for exploring the plausible influences of family policy on lesbian families and their children. The former group served as exploratory in that they have entered a new chapter in their lives wherein the option to marry is available whereas it previously was not feasible.

All of the women in the sample group were born in the United States. However, education levels and race/ethnicity varied. Three of the participants identified as African American, one identified as Native American, and the remaining 17 identified as Caucasian. Participants resided in Pennsylvania, New York, Virginia, Delaware, and Iowa. The participants ranged in extent of educational: four held Doctorate degrees, three held Master's degrees, ten held Bachelor's degrees, and 4 participants held high school diplomas. Participant age and legal status is presented in Table 1. 
Table 1. Participant Demographic Information

\begin{tabular}{|c|c|c|c|c|}
\hline Participant & Age & State of Residence & Access to Marriage & Legal Status \\
\hline $1 \mathrm{~A}$ & 33 & Pennsylvania & No & Married in NJ \\
\hline 1B & 25 & Pennsylvania & No & Married in NJ \\
\hline $2 \mathrm{~A}$ & 43 & Pennsylvania & No & No \\
\hline $2 \mathrm{~B}$ & 39 & Pennsylvania & No & No \\
\hline $3 \mathrm{~A}$ & 30 & Pennsylvania & No & Married in NY \\
\hline $3 \mathrm{~B}$ & 30 & Pennsylvania & No & Married in NY \\
\hline $4 \mathrm{~A}$ & 45 & Pennsylvania & No & $\begin{array}{l}\text { Registered Domestic } \\
\text { Partners in City of } \\
\text { Philadelphia, PA }\end{array}$ \\
\hline 4B & 37 & Pennsylvania & No & $\begin{array}{l}\text { Registered Domestic } \\
\text { Partners in City of } \\
\text { Philadelphia, PA }\end{array}$ \\
\hline $5 \mathrm{~A}$ & 39 & Delaware & Yes & $\begin{array}{l}\text { Civil union, became } \\
\text { legal } \\
\text { marriage in Delaware } \\
\text { July } 1,2013\end{array}$ \\
\hline 5B & 34 & Delaware & Yes & $\begin{array}{l}\text { Civil union, became } \\
\text { legal marriage in } \\
\text { Delaware July 1, } \\
2013\end{array}$ \\
\hline $6 \mathrm{~A}$ & 34 & Virginia & No & Married in MD \\
\hline $6 \mathrm{~B}$ & 35 & Virginia & No & Married in MD \\
\hline 7 & 48 & Delaware & No & $\begin{array}{l}\text { Married in Canada, } \\
\text { divorced }\end{array}$ \\
\hline $8 \mathrm{~A}$ & 42 & Delaware & Yes & $\begin{array}{l}\text { Civil union, became } \\
\text { legal marriage in } \\
\text { Delaware July 1, } \\
2013\end{array}$ \\
\hline $8 \mathrm{~B}$ & 38 & Delaware & Yes & $\begin{array}{l}\text { Civil union, became } \\
\text { legal marriage in } \\
\text { Delaware July 1, } \\
2013\end{array}$ \\
\hline
\end{tabular}


Table 1. Participant Demographic Information Continued

\begin{tabular}{|l|l|l|l|l|}
\hline 9A & 29 & Delaware & Yes & $\begin{array}{l}\text { Maryland, became } \\
\text { legal marriage in } \\
\text { Delaware July 1, } \\
2013\end{array}$ \\
\hline 9B & 29 & Delaware & Yes & $\begin{array}{l}\text { Maryland, became } \\
\text { legal marriage in } \\
\text { Delaware July 1, } \\
2013\end{array}$ \\
\hline 10A & 41 & Iowa & & Married in IA \\
\hline 10B & 40 & Iowa & Yes & Married in IA \\
\hline 11A & 30 & Maryland & Yes & Yes \\
\hline 11B & 31 & Maryland & Yes & Married in MD \\
\hline
\end{tabular}

\section{Sampling}

In order to obtain a sample for this study a combination of purposeful and snowball convenience sampling strategies were utilized. A sample of lesbian mothers having shared the experience, albeit different experiences, of living through marriage policy shifts were identified and recruited. By mindfully utilizing contacts I had made through networking online, within the GLBT community, publishing flyers in Philly Gay News, and through my experience with the Mazzoni Center in Philadelphia, a snowball convenience sample was obtained.

Initially, the sample was demarcated into two groups: lesbian mothers who had access to marriage equality juxtaposed with those lesbian mothers who did not have access to marriage equality in the states they resided. It became apparent as the study progressed that simply having access to marriage equality did not ameliorate the largest challenges faced by these lesbian mothers, and those categories had to be 
reworked. More specifically, it became evident that more categories were warranted, e.g., participants who had legal access to marriage but did not pursue it.

\section{Data Collection}

Semi-structured in-depth interviews were conducted after obtaining signed informed consent documentation (See Appendix C for original informed consent form) with the entire sample. Participants were prompted to share general demographic information as well as descriptions of their relationship, their partner, and their children (when applicable). Information pertaining to participants' countries and state (all United States born) of residence, ages, races and ethnicities, sex, marital statuses, and family size was also gathered.

The principle method of data collection was through semi-structured interviews. For the purposes of this study, general preliminary open-ended questions were developed (Please see Appendix A for semi-structured interview protocol). This was done to lay a flexible framework for the interviews while allocating the necessary flexibility to allow participants to respond fully (Daly, 2007). All of the interviews were audio-taped and then subsequently transcribed for coding and analysis.

Interview length varied between thirty minutes and two and a half hours. The average interview length was one hour. There were a total of 21 interviews conducted for this study, the first interview took place during July of 2013 and the last interview was held during November of 2013. Locations of the interviews were based on participant preferences as to facilitate comfort. The majority of the interviews were conducted in participants' home, barring geographic limitations (15 of the interviews 
were conducted in the participants' homes, 4 were conducted via internet chat/Skype, and 2 were held in public coffee shops selected by the participants). In addition to being audiotaped, field notes were taken during the interview process. All of the participants consented to being contacted as needed for clarification. Follow-up contact was done by a means of e-mail and telephone when necessary, and concluded by December 2013. Out of the entire sample of 21 , eleven were contacted a second time for clarification.

Furthermore, a field journal was kept to document scheduling, methods, and researcher reflections throughout the study (Lincoln \& Guba, 1985). The field journal aids the researcher in keeping a concise record of participants, responses, and personal reactions.

\section{Data Analysis}

For the purpose of data analysis, data were open coded as was collected (Glaser, 1967). Substantive, or open, coding refers to a means of bringing about emerging categories and conceptualizing data (Glaser, 1978; Strauss \& Corbin, 1998). Furthermore, Strauss and Corbin (1998) define axial coding as a series of procedures through which data are put back together in novel ways after the process of open coding has been completed. This was done to facilitate making connections between categories as well as to provide an understanding of the conditions or contexts that precipitate a category, or phenomena (Strauss \& Corbin, 1998). The coding procedure aided in exploring the relationships lesbians have with their families of destination while living in nearby areas with varying social policy regarding same sex marriage 
licensure. Furthermore, data provided an understanding of what it means to these couples to be denied the freedom to marry, to plan to marry, and in some cases, to marry.

Interviews with participants were recorded using a digital audio/voice recorder, and each interview was subsequently transcribed. Each of the transcribed interviews was read through multiple times to help discern meaningful statements and concepts. Margin notes were used to highlight significant statements made by participants about their experiences with the topic. These meaningful statements were set aside in a process referred to as horizonalization of the data (Given, 2008). Horizonalization consists of created segments of unique, separate, non-overlapping statements that are assessed as having equal value (Given, 2008). In succession, once lists of statements were compiled they were placed into groups based on the researcher's understandings of the transcriptions. The categories of meaningful statements were cycled back to participants for validation and clarification when necessary.

Explication of the data resulted in the evolution of a number of experiences and meanings in regard to same-sex marriage policy and daily life. Participant data provided descriptions of how the social phenomenon of same-sex marriage legislature shifts influence their lives. The procedure of contracting numerous hours of interviews into smaller groups of categories, themes, descriptions, and reflective notes made the data more manageable. Figure 1 illustrates the "data analysis spiral" as proposed by Creswell (2007). The delineation of the spiral portrays the circular and 
voluminous nature of qualitative research, in that it is not simply a linear process (Creswell, 1998; 2007).

Figure 1: Data Analysis Spiral

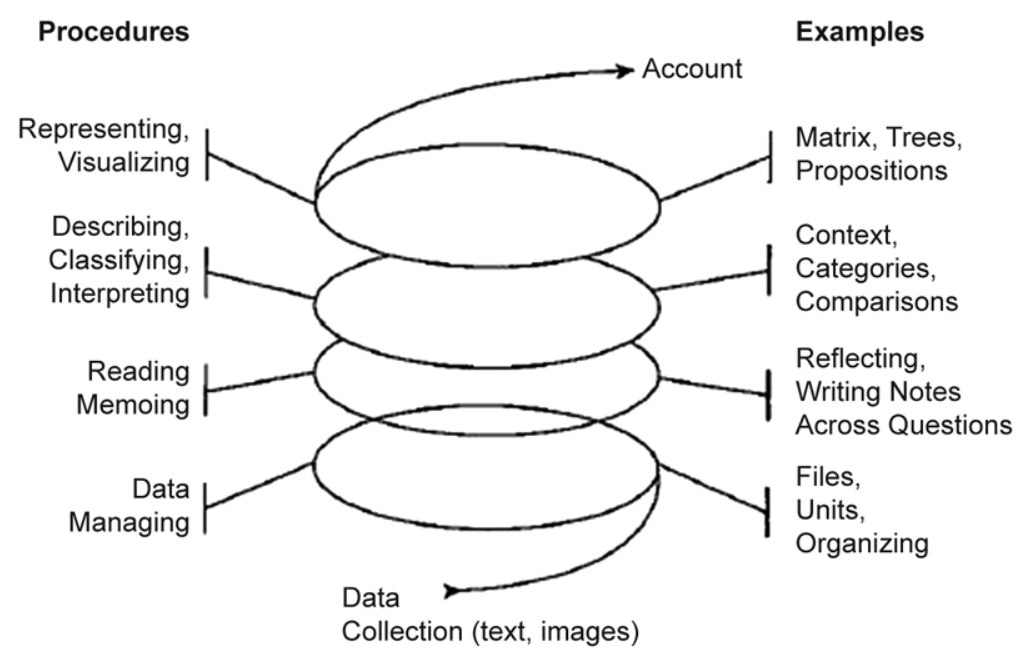

Source: Creswell (2007)

Furthermore, exploration of social phenomena warrants the maturation of descriptive data and themes (Creswell, 2007; Glaser, 1978; Strauss \& Corbin, 1998). Utilizing the meaningful data groupings as well as the full interview transcriptions, descriptive data were analyzed. For this study, descriptive data refers to the participant's account of their situation, their position within it, and its structure as situated within the larger society. Each set of descriptive data were treated as unique to the individual and case specific to their particular family. As a result, themes began to emerge from the data and were continuously cycled back to the researcher and the participants; both during the interviews themselves and via follow-ups post-interview. In accordance with axial coding guidelines, as novel emergent themes were 
discovered, they were understood in the context of previously collected data. In this regard, data were simultaneously analyzed and collected throughout the research process (Creswell, 2007; Strauss \& Corbin, 1998). This approach allowed the researcher to process new pieces of information in the context of the social phenomenon so that analysis allowed for synthesis of themes and a deeper understanding of the experiences of the participants (Lincoln \& Guba, 1985).

Additionally, while this study loosely employed grounded theory (Glaser \& Strauss, 1967) as a means by which to categorize and analyze emergent themes, the overarching framework was founded upon the recognition and acknowledgement of standpoint. Strauss (1987) posits that the use of literature as well as the self are the starting point of qualitative inquiry and that the researcher must remain sensitive to the meanings being conveyed by the participants.

\section{Ethical Reflections}

By nature, qualitative research is intrusive. As noted by Carrington (1999):

So many people gave graciously of their time and energy to the project that the final product seems more like a collective rather than an individual achievement... Most critically I wish to thank those who agreed to participate in this research and who opened their homes and family lives to observation and scrutiny (p.iv, acknowledgements).

With respect to the sensitive nature of the topic matter and vulnerability of the participants within this study, a number of measures were taken in an effort to protect the privacy of the participants and families involved. Upon submission to the University of Delaware's Institutional Review Board for expedited review the proposal was approved with the contingent addition of a family counseling resource telephone number to the informed consent page. Collection of data did not begin until approval was obtained. Informed consent was acquired from each participant, 
including the 4 interviews that took place via Skype/internet chat (see Appendix). In which case, the consent forms were mailed out with postage paid return envelopes and the interviews were not conducted until after the researcher had received the returned, signed consent forms. Throughout the research study consistent effort was made to protect the confidentiality of the participants. The participants were each assigned a pseudonym to allow the researcher to quote dialogue and ideas from the interviews while maintaining confidentiality. All digital audio recordings, reflexive entries and field notes were kept in a locked filing cabinet in a locked office space within the Department of Human Development and Family Studies on the University of Delaware campus.

Additionally, interview recordings have been kept confidential save to the researcher. More specifically, each interview recording was identified by number and interview date. A number of the participants communicated directly that they did not want any information that could be used to identify them printed or utilized. Noting that participants had been assured their identities would remain confidential the researcher employed an ongoing consent with participants. Research focusing on the ethics within qualitative research recommends maintaining ongoing, renegotiated consent with participants as to keep an open line of communication and understanding (Edwards, Mauthner, Mauthner, Birch, Jessop, \& Miller, 2002). This approach proved to be vitally important as two participants disclosed information they wanted to remain 'off the record,' and chose to share with the researcher only. With this in mind, the study results can be traced back to participants only through use of an interview 
number that only the researcher can access. Moreover, the results are presented in clusters and cumulatively by theme. This aids in safeguarding against readers from identifying patterns in the data that could plausibly allow them to discern the identity of participants. 


\section{Chapter 4}

\section{RESULTS}

Marriage has been a relatively universal social institution prevalent throughout recorded history (Coontz, 2005). To date, we are still without a commonly widespread definition of marriage. As conceptualizations of marriage continue to shift in contemporary American society, we have witnessed the development and progression of a debate surrounding what marriage is, what it should look like, and who should be allowed to attain it. As the results of these interviews demonstrate, marriage is a very complex entity that is met with varying levels of resistance and acceptance.

Discussed below are themes that emerged from the data. The experiences, opinions, perceptions and descriptions of this sample of 21 lesbian women will be presented in clusters, with relevant quotations when warranted. The elementary themes that came about from the data detail the relationship between the participants and the concept of marriage. These principal thematic categories and their secondary subthemes are illustrated in Table 1. The dominant themes that surfaced through the interviews were related to symbolism, status, and equal access to civil liberties. Upon further analysis, another layer of themes emerged that diverged from the researcher's expectations, pertaining to issues of guardianship, marriage as a false panacea/disadvantageous, disparate issues within the LGBTQ community, and selfadvocacy with the law. 


\section{Marriage as Symbolic}

One of the core tenets of this research study was to gain a deeper

understanding of how this sample of lesbian women perceived and navigated same-sex

marriage laws. Similarly, with that social inquiry comes the desire to explore what the institution of marriage represents for each individual.

Throughout the interview process participants expressed varying opinions in regard to marriage as an institution. Defining what marriage meant was admittedly difficult for each participant, as it carried with it a significant amount of weight, spanning across a number of domains in some cases. Fourteen of the 21 participants went as far to state they had never tried to articulate what marriage meant to them before the interview. Discussion of marriage as a social construct and how it was defined for participants individually proved to be of importance, as the one of the primary emergent themes was tied to participants' interpretations and understanding of marriage as a symbol, even if they could not attain it legally. With the exception of the divorced participant and one couple wherein both women were staunchly opposed to marriage, the remaining 18 participants voiced similar notions of what marriage represented to them in terms of symbolism. Several of the participants felt that marriage was rooted in an idea, and that the ideology surrounding it was about commitment, love, and family. For many of the respondents, the concept of what it is to be 'wed' to another was not tied directly to a change in legal status for all of the participants. One woman said, "I feel that committing yourself to that one person in front of friends and family is very meaningful, even if the government doesn't." In 
this regard, the lesbian women interviewed in this study traversed a different path to marriage or the marriage ideal. These experiences reflect a level of equifinality for the majority of the participants. Equifinality refers to the concept of multiple pathways resulting in a common end point (Lerner, 2006). Moreover, the varied and numerous pathways to marriage attainment for the participants, either legal or symbolic, proved to be telling of the pervasive nature of heteronormative discourse surrounding marriage itself. The majority of the participants held traditional viewpoints regarding marriage. In fact, a number of them held commitment ceremonies and weddings that reflected conventional heteronormative standards. Those expressing traditional ideas and definitions of marriage are best viewed in 2 subgroups, as a portion of these participants were readily aware of their alignment with traditional marriage proceedings and the remaining interviewees were surprised when the researcher pointed out the conventional nature of their ceremonies. Interestingly, those who were readily aware of their participation in traditional marriage norms (e.g., exchanging of vows, traditional wedding garb, and exchanging of rings) acknowledged the contradictory nature of their responses and referred back to marriage as being more about symbolism to them and less about social norms. After probing to encourage further definition of the construct of marriage, one participant exclaimed, "You know, I never really thought about it in that way before. Well, I think in some ways is about the fulfillment of dreams that some people had since they were children." Surprise upon clarification was particularly true for participants who had access to marriage and chose not to marry, or those that had marriage available to them in the state they 
resided when they chose to purse it. Approximately $25 \%$ of the participants further expanded their original responses upon follow up contact, stating they had given it more thought and one participant articulated the over-arching theme of an internal symbolism without governmental support, "My relationship has always been valid in my eyes, the legal marriage didn't change that for me." Similarly, another participant, who recently was able to access same-sex marriage in the state of Delaware noted that the symbolism and support was already in place before the law, "There are certain emotional things that didn't change, you know, we already had the emotional support, we had our families."

More specifically, when marriage was regarded as a symbol it was communicated as transcending the legal components. For example, one participant had a perspective shift when she met her current partner:

So before Kate when I heard the word it really meant little to me. Marriage could either be or not be. Now when I hear the word it makes me feel strangely proud and full. I love saying I am married and it is an incredible feeling to have that with Kate.

With this understanding comes the separation of legality from symbolism, and to a certain extent, the attempt to tease out the ties between private life and engagement with social institutions. A participant from a state denying same-sex marriage noted, "Yeah, so we're not legally married, so we're symbolically married." This statement reiterates that despite not having the structural support afforded to heterosexual couples, some of the participants still utilized the dominant vernacular when referencing the status of their relationship. This is of particular interest as it 
demonstrates that for the segment of this sample that wished to marry but could not attain it legally, marriage as a construct had been something discussed previously within their relationship, was something that had been given thought and attention, and as a result their responses were more articulate and specific than the portion of the sample that had been able to access marriage.

Additionally, for the participants in this study who wished to attain legal marriage and were unable to do so because of unsupportive laws, the response was most often to frame marriage around its symbolic features as those were separate from the law and readily accessible. One participant noted the function of symbolism, and what reframing marriage looked like:

I don't know, I mean, symbols are good, and I certainly believe in the value of longterm relationships for the right people with the right people. I don't need the government to help me with that part of my relationship.

Drawing upon the symbolic nature of marriage on a broader social level, one participant stated:

I am very comfortable with the institution of marriage. I don't like, I mean, I'm a feminist and I get like historically it's rooted and in patriarch you know all that stuff. But I feel like people negotiate commitment and commitment is synonymous with marriage, um for me. And so I'm not one of those people that like hates the institution of marriage. I think it's also hard to ignore the fact that, well, I think in some ways, a marriage validates a relationship in other people's eyes.

For many participants, regardless of legal standing with the law, their relationships provided a sense of stability and consistency. In fact, one participant currently living a state where marriage is not legal, but expressed no interest in becoming married even if it were to become legalized, stated: 
You know, just because I say marriage doesn't make sense to me that doesn't mean that I don't cry at other people's weddings, And that I don't love wearing a ring that sort of you know is this kind of public signal.

Twenty out of 21 participants explicitly referenced their relationships as being positive, supportive, or strong despite the lack of legal support. One participant living in a state where same-sex marriage is not accessible stated:

I feel like today I have this, um, relationship that is you know, the foundation, like a foundation for me and my family. And I feel like I've always wanted to be able to, you know, connect with another individual on a level that has the everyday, sort of the routine stuff, the boring stuff even.

When asked about discussions with their children, and how participants navigated both the overt and covert challenges as they pertain to same-sex marriage, the majority of the participants with children old enough to ask questions about the topic would approach it with hopefulness. For example, 6 of the couples had engaged in conversations with their children about marriage and their relationship. Four of the 6 had presented marriage as attainable for any type of adult couple, whether they be different sex or same-sex couples. When asked about how a participant and her partner responded when their son asked them about marriage, she noted:

We told him that we're married. So he knows that people get married. Um and then so and you yeah we've had the conversation that we've just said that girls can marry other girls and boys can marry other boys, which is sort of like a lie I guess, now that I depending on how you define it though. And obviously we don't rely on legal. Um yeah, I don't know, I just, I guess I just really value, um, the idea of marriage. But I also know, I mean I'm a sociologist, so I know how much marriage fails, whether it's legal or not. So for me it has been a learning process of what a marriage means and the hard work that it requires.

The other two couples in this sample that had engaged in conversation with their children went as far as to explain that currently marriage was not something that 
everyone was able to participate in, and with this variation came the difference of age of children by 4 years ( $10 \mathrm{vs} 14)$. This point illustrates a challenge presented to these lesbian mothers that is not entertained by heterosexual couples.

\section{Marriage as a Civil Right}

The second theme to be captured from the data was the understanding of marriage as a basic civil right that should be afforded to all citizens. This conversation took a decidedly different path with participants as they approached the institution of marriage as simply that. One participant, who had already had a commitment ceremony with her partner before the law was changed in Delaware, noted:

You know, our thought was that we had our ceremony and this is just more of, um, being official, or a paperwork kind of, it's not end-all, be-all kind of thing. It's, you know, we've already had it. This is just a formality.

Generally, referencing legal marriage as 'just a formality' is not part of the dominant discourse that surrounds marriage in contemporary America. This sentiment is one that is often reflected among cohabiting heterosexual couples, and emerged through the interview process for some of the participants in this study (Manning \& Cohen, 2012). However, all except for one of the participants that had celebrated their relationship by way of commitment ceremony, private ceremony, etc., and then proceeded to become legally married as it became available to them over time stressed the legal aspect as opposed to social symbolism. The outlier participant, who had recently become legally married in her state of residence referenced same-sex marriage as providing a level of social authentication for her relationship: 
Well, you know what, I will say one of the things I feel strongly about with this is that I feel like we're not second-class citizens. You know, like, I really think that it gives some validity to our relationship.

The notion of marriage as a legal arrangement that everyone should be offered choice of entering was prevalent, as one woman living in Virginia stated, "I think people should be free to legally bind themselves to one another. Do I think that all churches or private institutions should be required to conduct all ceremonies? No, I don't.” Continuing this point, another participant from a different couple stated:

My brother and his partner refuse to get married. They are straight, have 2 kids, are committed. It's their right to keep the law out of their relationship if they want to. Just as it should be my right to bind my relationship with the law.

Interestingly, the participant did not address the different custodial rights granted to married parents as opposed to cohabiting parents. In many ways, the law is still playing a role. For example, if the cohabiting couple mentioned by the participant were to dissolve and both desired visitation rights, they are not afforded the same rights as they would be had they been married. This demonstration of the gradient scale of legal consciousness within this sample of lesbian mothers reifies the intimate role the law plays in relationships sometimes unknowingly.

Additionally, with the articulation of marriage as a civil right came the argument for equal access to marital benefits. Participants lamented that by and large, the majority of the population did not understand just how many legal perks there are to obtaining marriage,

That's the other thing, is all the benefits that come with it and I think, that, you know, people don't realize how much does come with it. They take it for 
granted, because it's always been there and it's there if they want it, and, um, it will still be there if they don't want it.

This attitude towards equal rights via equal access to marriage was further supported by another participant who said, "It's discrimination, I mean, everyone should have the same right...but at this point it's nothing but legal for us." Keeping in mind, here the articulation of marriage and what participation in this institution meant was overshadowed by the legal dimensions. Alongside the legal ramifications of marriage acknowledged by the government came expression of simplification of tasks, especially financial tasks, "I tend to manage more of our financial stuff anyway, so now I can say well I'm her spouse so I need access to blank." One participant even stated that the vernacular surrounding marriage, or even use of the word marriage itself, was not critical for her or her family:

I mean, if I can have the same rights, I don't care, you can call it whatever you want. I mean, I know there's a lot of people that feel strongly, like, we need to have that. I want to be married, not because I want to be able to say that I'm married and label it, it's because my wife and I need the legal protection for our family.

Similarly, some participants who had originally been uninterested in participating in marriage, were hopeful that it would provide supports and needed protection for their families and children. "I felt like we were making a commitment, publically, that we intended to be together. Over time, my thoughts have evolved. Now, that we have children I feel like marriage is vital to our family's health." 
Additionally, participants noted that civil unions were not the same as being legally married and that it is unfair economically that she had to go through lawyers to obtain power of attorney and write out living wills:

But even when they did civil unions, that was a step, but I, you know, that wasn't really all of the rights. People don't understand. I was trying to explain to my brother that there were a lot of things that he doesn't realize, like people don't realize all of the tax benefits. The money! So much money, they have no idea, like, thousands and thousands in legal fees and that's just to get our property stuff in order, wills and stuff.

When pondering how or if it were feasible to offset the inequities that exist as a result of the significant tax breaks, economic, and legal benefits tied to marriage one participant from Pennsylvania described her ideal solution, "Yeah I think it might be even cooler to separate the government out of marriage altogether. So there would be no tax break for anyone." One lesbian woman, in a relationship of 9 years, who was staunchly opposed to marriage, but entertained the idea if it were to become legally advantageous:

I think I have a vocabulary that's more about commitment. Marriage and wedding and that stuff feels more to me like the legal apparatus. I feel pretty sure we wouldn't marry unless we got worried about certain kinds of protections. I know that sounds completely hypocritical, but so right now for example, like you know we live in this house that I think of as our house and yet, because of the laws in Pennsylvania are kind of screwed up, if I died, and you know the whole inheritance tax thing.

Continuing this point, in a separate interview the previous participant's partner used humor to cope with the fact that this may be part of their reality if the law continues to be unsupportive, "I can just see our little picture, you know, in the paper, stating we are getting married for financial reasons." Similarly, other participants referenced the 
seemingly arbitrary nature of the laws as they are currently situated, citing the example that her partner could obtain pet insurance for her dog but could not extend that to the relationship between humans, "I mean I remember being so frustrated and just thinking you know, Molly could get pet insurance to cover the dog's health but she couldn't get insurance to cover my health."

Conclusively, the lesbian women in the study that regarded marriage as a means to obtaining legal protections for themselves and their families recognized the profound impact of the benefits afforded to married couples. While the cumulative number of palpable benefits and perks to marriage towers over 1,100 (Hull, 2006; GLSEN, 2008; Patterson, 2009), one participant concisely stated, "marriage comes with so much but it's really for us, 10 really big benefits, and then countless little things." Similarly, this sentiment was reiterated by a number of participants. The most frequently mentioned benefits afforded by access and obtainment of legal marriage include: power of attorney, shared finances, tax breaks, property/asset perks, and facilitation of adoption/guardianship. These legal statutes come carrying a plethora of social benefits as well, however, the majority of the participants had compartmentalized each of these into different domains. Interestingly, some of the lesbian mothers had parsed apart these components after having a commitment ceremony (social aspect) while being unable to access legal marriage rights.

\section{Need for Federally Based Same-Sex Marriage Laws}

The decision to pursue marriage can take a number of pathways. Interestingly, these trajectories vary significantly for lesbian women. The lesbian mothers that 
participated in this study reported a number of variables that led them to seek marriage, when available, as well as a great deal of situational adversity that resulted from this pursuit. For example, for the participants living in states that granted samesex marriages, participants had to carry with them the understanding that their marriage was only valid in certain places, spaces, and contexts. As one participant explained, "Every time we would travel out of state it was very threatening to no longer feel like we would be recognized. It gave me anxiety to imagine something happening and me not being able to see Amanda and the kids." Clearly, this is not something a heterosexual married couple with children needs to think about, or plan for, when traveling within their own country of residence. There are significant disadvantages to state by state same-sex marriage laws.

The piecemeal success of the push for same-sex marriage legislature has made it increasingly difficult for couples to navigate the institution of marriage itself. As one participant from Pennsylvania described:

Marriage as an institution in itself, it's just, it's just so hard, and I do believe that I'd still be mad regardless of whether or not Pennsylvania got on board. The only thing that makes me mad about the whole state marriage, not federal, is that, you know, I pay more fricking taxes and stuff like that, right? So why can't they just agree to uniformly give everyone the same rights? I'm kind of like holding out for a federal. Um I just feel like this, I don't want to detract from anyone's experience, but I feel like the partial approach, all of that, that's how social change always happens, really um reduces what, it minimizes what she and I have.

More specifically, a participant living in Philadelphia within a registered domestic partnership expressed frustration with the laws, 
What I really want is for the city of Philadelphia to get its laws straightened out, so those kinds of things I think if I thought, oh if I am hypocritical and it saves you know, $\$ 20,000$, I may just be that hypocritical.

The same participant went on to reiterate that despite this consideration, marriage still was not something she and her partner wanted to actively pursue, "it's definitely not necessary for my relationship and yeah, I just really don't think the state should be regulating that part of my life." The experiences described by participants illustrated the internal conflict and ambivalence between varying levels of legal consciousness. Participants who stated they were fundamentally against participating in same-sex marriage found themselves entertaining the notion of situating themselves with the law, strictly for financial reasons.

Participants who had experienced disconnects between the microcosm where they live and surrounding states noted that a federal level shift is what is needed:

I know that it would have a great effect on my family. We are going to continue to live as the family unit that we are, and tie each other up in as many legal ties as we can to try and protect us, but marriage that was recognized everywhere would make everything a lot simpler.

Another participant's response reiterated this theme:

You know, it's like, you do your federal taxes and you split your relationship in half for tax purposes, so you get the kid, I get the house. It's ridiculous, and it takes months. I have got it down to a science where I do 4 or 5 what-if styled filings, and then we pick which one makes the most sense.

For a number of participants in this study it was not advantageous for them to marry in the state in which they reside, citing the interplay between custody issues and state level marriage laws: 
There would be a meaningful disincentive for us right now to get legally married because of financial aid for my daughter's in private high school, my son's in college. If we were married then Jen's finances would have to be part of the equation and I don't think that that's ethical you know, they aren't even legally her children.

Similarly, participants noted the excessive costs that resulted from having to outsource legal filings and tasks such as buying a home as a couple in a different state became difficult when marriage from one state was not acknowledged, "At one point, because we, when we were buying a house and selling a house and that kind of stuff, it actually cost us even more, because we had to file the same paperwork twice." Furthermore, some work environments that were viewed as being progressive by granting benefits to same-sex couples were not without unique financial ramifications, as one participant working in academia described:

The benefits for same sex couples here come with a huge financial penalty. Just because of the way our, um, our paystubs were written up. We just didn't make the connection. When I got my tenure track position it all became really complicated, because we aren't legally married here, it's not allowed. You know, we're fortunate enough, most of the people in our lives, like our pharmacy and stuff like that, they recognize us as a married couple. But all it takes is for one person to be off work and have a substitute in there, and then all of a sudden everything is a nightmare.

Everyday errands, like picking up medications or shopping for a family member had the potential to turn into negative experiences. A couple that moved from a state that granted same-sex marriage to Pennsylvania, where it is currently illegal, cited an issue during a routine visit to the Department of Motor Vehicles, "We tried to change my wife's last name on her license and are having issues with PennDOT since marriage isn't legal in Pennsylvania." Examples such as these demonstrate the unique 'negative 
spaces' (Daly, 2003) that exist for lesbian mothers. Furthermore, these examples

illustrate the inadequacy of our current policies as they influence families across state lines on a regular basis.

\section{Limitations of Legal Marriage}

Additionally, following the previous theme of marriage at the state level as being disadvantageous for many participants a theme emerged illustrating ideas and relationships that move beyond the institution of marriage itself. As one participant stated quite succinctly referring to marriage, "I like being in it, I mean, I like it at our house. Outside of my house with my family, it doesn't do anything for me." For some of the lesbian mothers in this study, marriage was less tied to their identification as lesbians in a committed relationship and more directly tied to their identification as mothers raising children together. Participants referenced their perspectives towards their relationship as being something separate than the traditional perspective that comes along with legal marriage:

Another part of what I resist about marriage is to death do you part. I think that's the wrong commitment. You know what we basically said to each other is we want to try really hard to stay together for as long as it's good for both of us. So I might sort of intellectually say marriage doesn't make sense to me for these reasons. Um, those are commitments I feel really good about making, uh, but I don't think, I yeah, I don't think til death do you part is the right one. And I don't think people should be set up to feel, uh, you know, like terrible failures if a relationship doesn't work out.

Participants in this study who felt that their relationship could not be supported, described, or fit within the parameters of traditional marriage did express support for others in terms of their relationships, as one participate stated, "I know plenty of 
people who are married that I feel happy-happy joy-joy feelings about their

relationships, but it isn't really about their marriage, it's more like ah, that's a good couple."

For others within the study, moving beyond marriage was the result of becoming educated about the institution and its long-reaching arms; and concluding it was not something they wanted to participate in:

I think we're both a little bit too over-read and politically charged to not think of marriage as already problematic, like a thing that already had too much economic stuff in it to begin with, so to like come full circle and then get married for financial reasons would seem as weird as weird gets. I just don't see us buying into it any time soon, it doesn't work.

Similarly, another participant drew upon the red flags she sees when she views Marriage as a whole:

The things that don't make sense to me about marriage, the reasons I would not be eager to do such a thing, um, I don't, I think a lot of the sort of legal roots of marriage, um, have to do with people making claims on one another. All of the parts of it tied to ownership, legal control, uh, and not necessarily freely given. Um, I don't, and the way that modern American culture is, I don't think we need that stuff.

Additionally, moving beyond marriage has deep roots in historical shifts that have occurred within the LGBT community for some of the participants in this study as demonstrated by one woman:

You know I came out in 1986 and there was a lot of rhetoric in the gay community, but more so in the lesbian feminist community, that marriage is a corrupt institution and we need to redefine marriage. Those kinds of relationships are hurtful to women and people in general and why would we want to imitate this thing and stuff, so, but I think there always was this underground movement that was kind of pushing towards that and there was a point where it was really starting to gain some ground. A lot of couples have been together decades without marriage you know, they don't need it. There 
was a lot of stuff, you know, stereotypes that gays and lesbians don't have long term relationships and such that marriage just couldn't apply to us. You realize now there have always been these couples that formed these lifelong relationships, you know, you read about the people who built that relationship against all of the odds. You never heard about them, they just have been together for 37 years, 47 years, whatever the case may be. When you start seeing that you start looking at services for seniors even, knowing that um, you know, long term care is a real concern. You know, these couples are trying to live their lives. Those sorts of things where it's not just about getting a marriage certificate it's about meeting all of these needs throughout the lifespan. I think we can meet those needs without traditional marriage, we just need the government to recognize our relationships in some other way.

As participants moved through the research process with the researcher, many of them began to reconcile this disconnect between their relationship situated within contemporary American culture and expectations surrounding the institution of marriage. As one woman described the difficulties she perceived with moving beyond marriage:

Um, and I don't think it would be entirely viable for the community to say well this is kind of been done for a while. Can't we just dissolve marriage altogether? Like, that's not going to happen. So, so that is not a way, a path to equality at the moment.

Moving beyond marriage became a focal point for many of the participants who had chosen not to enter marriage even if it were accessible to them, as well as for those who could not access legal marriage, and some of the lesbian women who had entered the institution of marriage. One optimistic participant viewed the move beyond marriage as being something that will inevitably permeate all segments of the population:

I could imagine that this may be that, that, that same-sex marriage equality potentially becomes a step. You know, it might, it might be part of an evolving, cultural evolution that maybe eventually does take us to the point 
where we don't have legally binding marriages in the same way anymore because the, you know, the majority of the culture has caught up to some of the rest of us who I think are asking really appropriate questions about whether this is really what we ideally want.

A portion of the sample was less optimistic about same-sex marriage as paving a road to cultural evolution and shifts around how individuals manage their relationships. Moreover, of particular interest was the concern over whether or not the legalization of same-sex marriage is actually a hindrance to lesbian couples that either choose not to participate or cannot for other reasons. One participant described a similar scenario:

I worry about where this is heading, especially if we end up in this weird wrap around kind of thing where lesbian couples who don't get married start to be more disenfranchised than we already are because people are saying, well you could've gotten married why didn't you.

This particular example clearly demonstrates the importance of the interplay between awareness and accessibility. For many participants working before, with, or against the law was a conscious choice (Ewick \& Silbey, 1998); however, for some it was simply not an area where they actively expended energy. What is perhaps most alarming about this discrepancy is the realization that lesbian mothers living in states where same-sex marriage is accessible that are opting not to marry may be slighted in other ways via the law or social norms. In this regard, another similarity between gay fathers and cohabiting heterosexual couples was evident.

\section{Dominant Concerns within the LGBTQ Community}

While same-sex marriage may be the LGBTQ issue that is garnering the most media and political coverage recently, it is certainly not the only arena where LGBTQ 
individuals experience adversity. When asked whether or not the continued push for obtaining same-sex marriage rights should be first priority for the LGBTQ movement and community, a resounding 17 participants agreed that albeit important, it is not the most salient contemporary issue within the community. This finding was unexpected and the responses regarding what matters are of primary interest varied but tended to intersect issues of quality of life. For example, one participant living in a state that does not currently grant access to marriage for same-sex couples noted:

You know I mean I, I think, um, I can certainly appreciate the impulse that, you know if straight couples can do this then we should be able to. I just don't think it's the direction we should take it. I would rather see the community working towards equality for everyone, not just folks that want to get married.

Extending rights and protections that would impact more than just the portion of the LGBTQ community that wishes to participate in legal marriage became a dominant theme. Some participants quite plainly stated that they did not feel obtaining equal access to marriage would in any way help offset other social inequities faced by marginalized LGBTQ individuals and families, for example, on participate stated, "I don't think that same sex marriage is the vehicle to eliminate hate." While other participants cited grave examples of friends lost to violence and/or harassment against LGBTQ, as one participant noted, "There are far more important things. You know, there are people who just aren't surviving day to day."

Furthermore, as this theme emerged it became readily apparent that the lesbian women in this sample felt strongly about equal protections as citizens and human beings. A number of the participants referenced hate crime and anti-discrimination 
legislature, as stated by a participant from Pennsylvania, "We're all moving in the right direction, um, but, I, I really feel strong, really about having the antidiscrimination laws in effect, because I think that can do more damage than not." This quotation draws upon Bogenschneider's (2006) acknowledgement that the policies we lack are more telling than those we choose to uphold as a society. More specifically, that it is a reflection of larger issues undermining the fight for equality, and that no matter how many policies we amend we are still missing fundamental protections for entire groups of marginalized people in our society, as noted by a lesbian mother:

Although I do think politically for the queer movement, like I think we focus too much on marriage sometimes, and we've other issues that are more important. As far as my community, I'm really concerned about hate violence, I'm really concerned about trans people, and I'm really concerned about healthcare, you know?

Along with expression that access to same-sex marriage is not the most prominent issue facing the LGBTQ community came the understanding that the intersection of inequities presented a more complicated view of current social conditions. For example, the intersection of LGBTQ individuals who identify as gender variant presents a unique predicament, as one participant described:

Poverty is real issue. Members of the trans community have such a hard time finding work, and the high rates of incarceration, you know, you can be arrested as a trans or gender queer person just for using a bathroom.

In this way, issues pertaining to fundamental, rudimentary facets of life such as employment, or utilizing a public bathroom juxtapose access to marriage demonstrated that others are engaged in battles on different levels. Moreover, that marriage, even when legal, becomes an achievement for segments of the population outside of the 
dominant heterosexual majority. Marriage as an achievement, only pursued and managed by a portion of the population, is not new knowledge (Cherlin, 2004).

However, within the same-sex marriage debate, and the LGBTQ movement itself, marriage has a different meaning from what is understood in the mainstream. Consequently, these varied understandings of what marriage entails is the underlying theme of the discord that exists within the LGBTQ community. As participants noted, for many individuals obtaining access to legal marriage is not seen as a priority when simply surviving day to day is part of the reality. The notion of marriage as an achievement takes on a multi-faceted meaning when proponents of same-sex marriage are spearheading its widespread acceptance, seemingly at the expense of other issues.

\section{The Challenge of Guardianship for Lesbian Mothers}

The theme that emerged and ran throughout the majority of other areas of concern and struggle for the lesbian women in this sample was that of issues surrounding guardianship. The entire reality of this was brought to light by the juxtaposition of varying state policies regarding adoption laws and marriage legislature. As one participant declared outright after being asked what the biggest challenge she currently faces as a lesbian mother, "My biggest problem is that I have no legal rights to my daughter." This sentiment was reiterated, to varying degrees, by 15 of the 21 participants in this study, with some of the women giving worst-case scenarios to demonstrate the severity of the issue, "What happens if we decide to split, hypothetically? I have no legal protection when it comes to custody." 
The lack of legal support offered to lesbian couples with children is analogous to that afforded to cohabiting fathers, gay or heterosexual. When comparing the legal protections, rights, and issues faced by men and women in different kinds of relationships a number of similarities and differences can be observed depending upon geographic location. For example, a study examining premarital cohabitation and marital dissolution among heterosexual couples found that martial commitment in the form of definite plans to marry or engagement prior to cohabiting was correlated with lower martial instability among women, but not for men (Manning \& Cohen, 2012). Hypothetically, in this regard cohabiting with future plans to participate in the institution of marriage may act as a protective barrier for heterosexual women, whereas for lesbian women who cannot marry legally it may present a different issue. Research has demonstrated that cohabitation has become an elemental part of the marriage process for nearly $2 / 3$ of heterosexual newlyweds who felt that doing so helped to ensure stable marriages (Manning \& Smock, 2009). The issues surrounding the trajectory of cohabitation and subsequent same-sex marriage where legally permissible for lesbian couples with children has yet to be fully addressed. The participants in this study expressed legal and economic concerns as they related to cohabiting in states where their relationships were not acknowledged by the law; which is a frustration often expressed by cohabiting heterosexual fathers (Poortman \& Mills, 2012). Similarly, one woman, married in a state separate and not acknowledged from her state of residency, stated: 
Virginia doesn't allow single parent adoptions. They don't recognize our marriage in Maryland. I have power of attorney for Jill and she has a living will which names me a guardian if she is incapacitated, but at this point, I have zero legal rights to my daughter.

The understanding of how to navigate legal loopholes demonstrated the gradient scale of legal consciousness that was present among the sample of participants. For the lesbian mothers who had the economical wherewithal to secure living wills, power of attorney, pay for home study visitations that are required with the adoption process, weaving in and out of the laws to their own advantage was an option. Interestingly, cohabiting heterosexual couples with children are faced with similar hurdles in terms of securing legal protections for themselves and their children. However, the legal consciousness of heterosexual cohabiting couples and lesbian couples is not a monolithic experience (Harding, 2006). Furthermore, the history shared among lesbian women of fighting for rights and protections is a unique one that falls outside of the heteronormative sphere in some regards, and has implications for heterosexual cohabiting couples that may assume the law supports them outside of marriage (Case, 1993; Oswald \& Kuvalanka, 2008). While some of the women in this study were readily aware of steps that needed to be taken to secure legal protection and guardianship, they lacked the financial resources to take them. For example, one mother living in a state that allowed for same-sex marriage but did not have guardianship over her daughter cited financial restraints as being the primary challenge to filing for adoption: 
We keep bringing up that we need to do the adoption. But that's a lot of money. And, like, the home study, and there's jus, it's a lot of lawyers, and it's a lot of money, and we just don't have that money right now.

This perspective resonated with others, who felt the same regarding the financial strain of separately filing for second parent adoption:

I mean it was really hard, and costly. We had to pay $\$ 1000$ to have a home study done. And his, uh, donations, or his specimen has gone up quite a bit, so, now when we think about having another child we have to think about how much more it is going to cost the next time around. So that way if something did happen to one of us, technically, you know, in the law's eyes they couldn't separate the siblings.

The issues surrounding guardianship clearly went beyond the adoption process, and in some cases extended into the realm of insurance plans and hospital visits, as onmother described, "I have great insurance at work. The new baby will be able to be on my policy. Jackie and Lee are not. We have to buy their insurances plans privately." While the legal benefits of marriage are readily apparent, through the interview process some of the social affordances emerged as well; as one mother living in a state that does not grant or recognize same-sex marriages illustrated:

We had to take her to the hospital for her to get stitches. The technician came in to ask a thousand questions before they could start. One of the questions was 'are you her mother?' Yes, of course I am, but no, not legally.

Moreover, participants cited confusion and frustration when trying to complete the necessary steps during routine doctor's visits or surprise hospital visits. Taking into consideration the lack of structural support, some lesbian mothers are forced to create their own solutions, as one mother described: 
When we went through fertility treatments, I wrote my name on all the lines for the father. I know this doesn't help anything, but we wanted to leave a paper trail showing our intention. But would that actually mean anything? No, it wouldn't.

Similarly, in a separate sphere of daily life, a lesbian mother recounted an experience filing for her daughter's day care arrangements. The organization was not prepared to address same sex couples, even though the participant was employed there, since she was not legally tied to her daughter it presented a challenge:

They um, needed something, or some kind of legal document. And they couldn't tell me, like, what they needed. So the real deal, you know, and then I actually ended up, I had talked to a lawyer about this, because it was a discrimination case, because in this case, in my case, they wanted some legal documentation, but in no other case did they ever ask for legal documentation. Originally, they were going to let me take three months off of work. This is the funny thing is, they were going to let me take three months off for the birth of a child that wasn't legally mine. So they were going to give me my three months off. But she's not mine. But it really is, it's huge. Then it came time to start doing the paperwork to get her enrolled in the actual care program and they said no because she wasn't legally my daughter and wanted all kinds of paperwork, that they never requested from straight couples, so I quit. How could I go back? They discriminated against my own family.

For others, their selected timing of entering into the institution of marriage or in some cases a civil union or domestic partnership proved to work against them over time in terms of guardianship and legal adoption. One participant living in Delaware who had entered a civil union with her partner before same-sex marriage was an option realized even though civil unions became legal marriages in the eyes of the law this did not extend itself to adoptive laws:

I just kept asking what, like, what do I need to do, or does that, how does that affect, like, me and Molly's legal status, or whatever. And then he said, well, because you had her before the civil unions went through, you have to go 
through the adoption. So it's just a matter of doing it. And my wife doesn't think anything of it. She's like, "Well, of course, yeah, she's ours." You know, but I'm like, "Yeah, but legally, she's not."

In this instance, working with the law initially proved to be untimely in terms of guardianship concerns. More specifically, experiences such as those of the participants in this study demonstrate that there is no socially prescribed on-time transition to marriage for lesbian couples. Many lesbian women navigate this terrain of their own volition and in some cases the law supports them, while in others it functions as a detriment.

For others, the challenges they faced as lesbian mothers were larger in scope, and permeated multiple facets of daily family life. For one participant raising a son through the changing in state-level marriage legislature, it was more about systematically attaining equality on the legal level:

We wanted to do everything we could to approximate what everybody else had and yeah I think we're more, I think those of us in the community are more realistic as a result of having to seek out and obtain every little right and protection. We have to be, yeah. It's just like we have to plan our pregnancies, you know, so we think about it a lot. I think there's something to be said for that.

Additionally, some of the challenges faced by lesbian mothers in this simple pertained to fundamental aspects of family dynamics. For example, interacting with other family members who are not familiar with same sex couples or aware of the arduous processes that transpired to create a family, as one participant noted, "People forget that Tom isn't biologically tied to me, you know, my dad has slipped and said he has my hair. Which is the outcome we wanted, but still it's hard sometimes." 
Perhaps most importantly, participants noted that they needed to seek out extraneous protections in a variety of different ways to allow them some of the same legal buffers as marriage. For a number of participants, this meant filing paperwork for a change in last name to facilitate interactions with medical and school personnel. A participant from Virginia noted that even this process was not always simple:

Once our daughter was born, we wanted our names to reflect our family. So we decided to give our girl my name as one of her middle names. My partner legally changed her name to include my name as her middle name. I filed to change my name too, adding her name as my surname and the judge rejected my petition. Even though both she and I went separately into his chambers and gave him the same explanation, he accepted her request and denied mine. He said that I was purporting myself as married, which I am not in Virginia. So, um, if I had said I wanted to change my name because I like it, because it's pretty, or because I wanted to, he would've allowed it. Yeah, so luckily the ACLU defended my case. They enlightened him to the fact that many people have the same last name and are not married.

As illustrated by the narratives of the participants, issues pertaining to the legal guardianship of children presented significant adversity. Furthermore, as this theme emerged it was often accompanied by peripheral issues surrounding legal benefits afforded by marriage. More specifically, laws at both state and federal levels pertaining to adoption and guardianship were regarded as the "biggest problem" faced by the majority of the lesbian mothers in this study. Similarly, custody is a salient issue within heterosexual marriages and divorce, and is one that warrants a reevaluation of our current legislature. 


\section{Chapter 5}

\section{DISCUSSION}

The purpose of this study was to explore how legal consciousness of lesbian parents with children in marriage equality/inequality states impacts perceived stigma/social acceptance as well as daily life. This study aimed to address the following research questions:

1) How does marriage equality/inequality affect the daily lives of lesbian families?

2) How are policy/social barriers in reference to same-sex marriage discussed across generations within lesbian families?

3) What perspectives do lesbian couples have on the impact of changing policy on their own relationships? In other words, does participation in, or rejection of, the institution of marriage change how they view their own families, their hopes/plans for the future?

The goal was to apply the framework of legal consciousness (Ewick \& Silbey, 1998) in order to build upon and expand the limited body of knowledge regarding how same-sex marriage legislature, or lack thereof, influences lesbian family life on both public levels and within academia. Insufficient academic attention has been devoted to the issues of lesbian mothers across the United States. Interestingly, these conversations are happening informally within the LGBTQ community, and have been for quite some time (Card, 1996; Rich, 1980; Clarke, 2003; Lewis \& Gossett, 2008; Hopkins, Sorensen, \& Taylor, 2013). 
Approximately 1.5 million lesbian women are raising children under the age of 18 in the United States today (Census, 2010). More specifically, current statistics indicate that $48 \%$ of lesbian couples are raising children together (GLSEN, 2008). Furthermore, same-sex couples are 6 times more likely than their heterosexual counterparts to be raising foster children (GLSEN, 2008). While these numbers are difficult to estimate, it is apparent that lesbian women are becoming mothers despite a lack of governmental and social supports.

The research described in this study illustrates the continuum of varying experiences of lesbian mothers with respect with to in regard to accessibility to legal marriage. Additionally, this study provided the necessary step towards deepening our understanding of how state-level marriage rights are conceptualized and navigated by lesbian mothers living in varying parts of the country. This study also provides insight into the experiences each participant has had as well as their own expectations for the future: as individuals, relationship partners, and mothers. The detailed narratives of the participants allow the researcher to draw connections to theory and inform policy.

A qualitative approach was employed in order to examine the daily challenges faced by lesbian mothers as their lives intersected with the law. While research in this area has recently begun to augment, our understanding of the fundamentally subtle nuances within the lives of these lesbian mothers has yet to be conveyed academically.

This study included interviews with 21 adult lesbian women; 9 couples with children, 1 couple in the processing of trying to become pregnant, and 1 divorced lesbian mother. The larger sample with varied positions in terms of motherhood and 
relationship status provided a wealth of information in terms of understanding the implications of marriage.

The nature of this study warranted a qualitative approach, as semi-structured in-depth interviews provides a wealth of knowledge and an exclusive vantage point for investigating the relationship between family policy and family life within this subgroup of the greater population (Flick, 2006).

With respect to the data, it is important to note the limits of the framework of legal consciousness as provided by Ewick and Silbey (1998). The results of this study indicate that, in a number of ways, the law does not matter in the lives of the lesbian women who participated. More specifically, the triangular framework situating individuals before, with, or against the law illustrates that legal marriage itself is insufficient in fostering complete equality for this sample of lesbian women. However, it is critical to note that at other junctures, the law is vitality important. The data demonstrate that the ternate framework of legal consciousness lends itself to better understanding issues pertaining to guardianship, as many of the participants found themselves "before the law" or "against the law" in terms of adoption of nonbiological children and co-parenting.

\section{Discussion of Theoretical Framework}

The goal throughout the entire data collection process was to allow the participants to convey their understanding of marriage, their thoughts and opinions regarding the institution itself, and their experiences living as lesbian mothers in the United States. Several theoretical perspectives provided lenses and proved to be 
advantageous in aiding to situate the descriptions given by the participants. This unique combination of theoretical frameworks created a foundation to help address the complex nature of each participant and family.

\section{Feminist Standpoint Theory}

Feminist theory was helpful in aiding the researcher in critically analyzing the dominant cultural ideologies within which the participants are situated. Furthermore, this perspective was useful as it providing a reference base for illustrating the social phenomena of changes in same-sex marriage legislature as it pertains to the individual lives it influences, as opposed to served establishments or institutions (Harding, 1987). Additionally, standpoint theory (Harding, 1986) branched out of feminist thinking regarding different positions held by women in society. Even within the LGBTQ community, lesbian mothers hold varying places in terms of acceptance by the larger, heterosexual population. This point was highlighted throughout the results of the study, as participants ranged in their accessibility to marriage, their willingness to participate in the institution itself, and in their access to resources necessary to seek out legal protections for themselves and their families. Similarly, this theory states that the position of women, which is generally subordinate, ultimately affects their view of the world. Two important points proposed by this theoretical framework that were particularly relevant to this study, the need to hear the "voices" of people regardless of their race, class, sexuality, and gender, and increasing sensitivity to social positions within various societies (Adams \& Phillips, 2006). This research aimed to provide voices and relay the narratives of the participants in meaningful ways 
to help deepen our understanding of the influence of marriage policy academically, within our communities, and on a legal level. It is through contributions of standpoint epistemology and reflective practice (Naples, 2003) that this study produced rich narratives that highlight new, detailed angles of the everyday lives of this sample of lesbian mothers, in committed relationships, situated in varying environments of social policy at the state-level.

\section{Critical Social Theory}

Similarly, critical theory has worked to counter the marginalization and stigmatization of subgroups within the population (Fay, 1987). Traditionally, critical theory has stressed the importance of questioning society, institutions, and cultural norms (Bernal, 1967; Fay, 1987). Within the scope of this research study, the social crisis is understood to be one of access to equal rights via marriage law, and the transformative action(s) are changes in legislation in varying parts of the country. Moreover, this theoretical approach engaged both participants and the researcher in reflective, critical evaluation of the interplay between far-reaching social, political, and economic systems and everyday life (Dante, 2003; Freeman \& Vasconcelos, 2010; Lather, 1986). Within this particular study, participants drew upon their own experiences over time as well as their understanding of social justice, equality, and advocacy.

\section{Life Course Theory}

Lastly, life course theory is helpful in learning about families and transitions over time. More specifically, the life course perspective accentuates the timing and 
sequence of transitions (Elder, 1998; Hareven, 1987). Life course theory acknowledges that transitions have varying meaning depending upon when they occur during the life course and where they are situated with other sequential life events (Amato \& Kane, 2001; Elder, 1998; Hareven, 1987). Parenthood and marriage are examples of such transitions, and the timing of these events can be regarded as "on time" or "off time" depending on social and cultural norms. For lesbian mothers in the United States, legal marriage has only recently been viewed as a viable transition. Where this transition is situated within the life course for these women and their families has yet to be determined, along with whether or not this is a transition lesbian mothers choose to make. Furthermore, these families will face other legal problems over the life course, e.g., trusts and living wills, which will need to be navigated.

\section{Thematic Integration}

Throughout the research process, themes were categorized as they emerged from the data. As the research progressed, some of the most prevalent themes were unexpected by the researcher. Integration of these themes enables the researcher and participants to understand the legal enmeshment that comes with participation in the institution of marriage but also an understanding of the legal limitations of marriage. In this regard, legal consciousness is simply not enough to empower lesbian women in the United States. Furthermore, synthesizing themes allows for a more developed, multi-faceted representation of the experiences of the participants.

The first emergent theme to be captured from the data was the notion of marriage as a symbol. Among the 21 participants, definitions of symbolism included 
both physical, tangible items such as rings as well as representation of ideas and values. However, upon further exploration the discussion that surrounded how the construct of marriage was defined proved to be vitally important. Fourteen out of the 21 participants stated they had not previously tried to articulate what marriage meant to them verbally. Several of the participants felt that marriage was rooted in an idea, and that the ideology surrounding it was about commitment, love, and family. For many of the respondents, the concept of what it is to be 'wed' to another was not tied directly to a change in legal status for all of the participants. As one participant stated, "I feel that committing yourself to that one person in front of friends and family is very meaningful, even if the government doesn't." In this regard, the lesbian women interviewed in this study traversed a different path to marriage or the marriage ideal. With the exception of the divorced participant and one couple wherein both women were staunchly opposed to marriage, the remaining 18 participants voiced what marriage represented to them in terms of symbolism.

To the researcher's surprise, the majority of the participants held traditional viewpoints regarding marriage. In fact, a number of them held commitment ceremonies and weddings that reflected conventional heteronormative standards. Those expressing traditional ideas and definitions of marriage are best viewed in 2 subgroups, as a portion of these participants were readily aware of their alignment with traditional marriage proceedings and the remaining interviewees were surprised when the researcher pointed out the conventional nature of their ceremonies. Interestingly, those who were readily aware of their participation in traditional 
marriage norms (e.g., exchanging of vows, traditional wedding garb, and exchanging of rings) acknowledged the contradictory nature of their responses and referred back to marriage as being more about symbolism to them and less about social norms. In other words, the overwhelming majority of participants desired to participate in traditional marriage norms, and saw themselves as being similar to other couples in this way, regardless of being in a same-sex relationship.

Participant perceptions of the institution of marriage changed when marriage was discussed as a platform for equality. The second theme to emerge from the data was the understanding of marriage as a basic civil right that should be afforded to all citizens. This conversation took a decidedly different path with participants as they approached the institution of marriage as simply that. One participant, who had already had a commitment ceremony with her partner before the law was changed in Delaware, noted:

You know, our thought was that we had our ceremony and this is just more of, um, being official, or a paperwork kind of, it's not end-all, be-all kind of thing. It's, you know, we've already had it. This is just a formality.

Referencing legal marriage as 'just a formality' is not part of the dominant discourse that surrounds marriage in contemporary America. Consequently, the wide spectrum of perceptions of legal marriage spanning all segments of the population leaves marginalized subgroups, such as lesbian mothers, on the precipice of further desensitization towards marriage as an institution. However, all except for one of the participants that had celebrated their relationship by way of commitment ceremony, private ceremony, etc., and then proceeded to become legally married as it became 
available to them over time stressed the legal aspect as opposed to social symbolism. With the articulation of marriage as a civil right came the argument for equal access to marital benefits. Participants lamented that by and large, the majority of the population did not understand just how many legal perks there are to obtaining marriage.

Similarly, other participants referenced the seemingly arbitrary nature of the laws as they are currently situated, citing the example that her partner could obtain pet insurance for her dog but could not extend that to the relationship between humans, "I mean I remember being so frustrated and just thinking you know, Molly could get pet insurance to cover the dog's health but she couldn't get insurance to cover my health."

Conclusively, the lesbian women in the study that regarded marriage as a means to obtaining legal protections for themselves and their families recognized the profound impact of the benefits afforded to married couples. Throughout the interview process, participants negotiated their own understanding of marriage as a social construct carrying symbolic weight juxtapose marriage as a social institution carrying legal ramifications. The interplay between participating in traditional marriage ceremonies and employing marriage as a tool to access rights presents a trajectory that is not part of the dominant contemporary heterosexual discourse.

Consequently, the lesbian mothers that participated in this study reported a number of variables that led them to seek marriage, when available, as well as a great deal of situational adversity that resulted from this pursuit. As one participant explained, "Every time we would travel out of state it was very threatening to no 
longer feel like we would be recognized. It gave me anxiety to imagine something happening and me not being able to see Amanda and the kids." Clearly, this is not something a heterosexual married couple with children needs to think about, or plan for, when traveling within their own country of residence.

The piecemeal success of the push for same-sex marriage legislature has made it increasingly difficult for couples to navigate the institution of marriage itself. Participants described expected and unexpected challenges to obtaining marriage in states where it was currently granted, including issues traveling or moving over state lines to less amenable circumstances.

The experiences described by participants illustrated the internal conflict and ambivalence between varying levels of legal consciousness. Participants who stated they were fundamentally against participating in same-sex marriage found themselves entertaining the notion of situating themselves with the law, strictly for financial reasons. Participants who had experienced disconnect between the microcosm where they currently live and surrounding states noted that a federal level shift is what is needed.

Similarly, participants noted the excessive costs that resulted from having to outsource legal filings and tasks such as buying a home as a couple in a different state became difficult when marriage from one state was not acknowledged, "At one point, because we, when we were buying a house and selling a house and that kind of stuff, it actually cost us even more, because we had to file the same paperwork twice." 
Everyday errands, like picking up medications or shopping for a family

member had the potential to turn into negative experiences. A couple that moved from a state that granted same-sex marriage to Pennsylvania, where it is currently illegal, cited an issue during a routine visit to the Department of Motor Vehicles, "We tried to change my wife's last name on her license and are having issues with PennDOT since marriage isn't legal in Pennsylvania." This intersection between preconceived notions of governmental support via marriage moving quickly from existent to invisible on a daily basis were more pronounced for some participants than others.

Consequently, once again these gaps in consistency across state lines and even across days in some cases prompted a number of participants to look beyond marriage. The thematic conceptualization of moving beyond marriage branched off of the previous theme of marriage at the state level being disadvantageous for many participants. As one participant stated quite succinctly referring to marriage, "I like being in it, I mean, I like it at our house. Outside of my house with my family, it doesn't do anything for me." Participants referenced their perspectives towards their relationship as being something separate than the traditional perspective that comes along with legal marriage.

Similarly, participants in this study who felt that their relationship could not be supported, described, or comfortably fit within the parameters of traditional marriage did express support for others in terms of their relationships, as one participate stated, "I know plenty of people who are married that I feel happy-happy joy-joy feelings about their relationships, but it isn't really about their marriage, it's more like ah, 
that's a good couple." For others within the study, moving beyond marriage was the result of becoming educated about the institution and its long-reaching arms; and concluding it was not something they wanted to participate in. Within this particular sample, it was difficult to identify which participants could be categorized as outliers in this regard, or as typical; as it begged the question of what is typical? Insomuch as looking beyond the legal component or marriage, it is this interplay between the legal structures that are seen as prohibitive for some and the social aspects that forge varied and sometimes adverse terrain for these participants to navigate as women, as lesbians, and as mothers.

Additionally, moving beyond marriage has deep roots in historical shifts that have occurred in the LGBT community for some of the participants in this study as demonstrated by one woman:

You know I came out in 1986 and there was a lot of rhetoric in the gay community, but more so in the lesbian feminist community, that marriage is a corrupt institution and we need to redefine marriage. Those kinds of relationships are hurtful to women and people in general and why would we want to imitate this thing and stuff, so, but I think there always was this underground movement that was kind of pushing towards that and there was a point where it was really starting to gain some ground. A lot of couples have been together decades without marriage you know, they don't need it. There was a lot of stuff, you know, stereotypes that gays and lesbians don't have long term relationships and such that marriage just couldn't apply to us. You realize now there have always been these couples that formed these lifelong relationships, you know, you read about the people who built that relationship against all of the odds. You never heard about them, they just have been together for 37 years, 47 years, whatever the case may be. When you start seeing that you start looking at services for seniors even, knowing that um, you know, long term care is a real concern. You know, these couples are trying to live their lives. Those sorts of things where it's not just about getting a marriage certificate it's about meeting all of these needs throughout the 
lifespan. I think we can meet those needs without traditional marriage, we just need the government to recognize our relationships in some other way.

As participants moved through the research process with the researcher, many of them began to reconcile this disconnect between their relationship situated within contemporary American culture and expectations surrounding the institution of marriage. Interestingly, the interplay between the disconnection of current marriage policies and social expectations around marriage and parenthood prompted the development of unexplored negative spaces. The term negative spaces was applied by Daly (2003) to assess the daily family activities that are commonly ignored in research. In this particular instance, the experiences of the lesbian women interviewed for this study illustrated unique negative spaces that exist for them as lesbian mothers.

The most prominent theme to emerge throughout the interview process was that of guardianship issues faced by these lesbian mothers. This finding was most surprising to the researcher, who entered the study with the understanding that marriage equality would help ameliorate some of the daily struggles for many lesbian mothers. This finding can be interpreted as readily illustrating the shortcomings of family policy as it currently stands in the United States. This study lends itself to providing the researcher with an unprecedented vantage point from which to understand the influences of policy on this sample of lesbian mothers. Resoundingly, what was conveyed by these participants was that the law, irrespective of legal consciousness as it pertains to marriage policy, falls short in terms of parenthood. This experience is similar to those of other sub groups within the population, e.g., 
cohabiting fathers. However, for the lesbian women in this study, the social experience is inherently different, and therefore, the experiences of navigated social institutions such as the court system are not synonymous for each group. This disparity warrants the attention of policymakers in terms of guardianship for individuals who are not legally tied to their children via marriage and/or have no biological ties to their children, with particular attention given to those whom meet both of the aforementioned criteria. The voices of the lesbian mothers in this study demonstrated that in terms of legal support there is no unilateral solution or piece of legislation that will assuage these problems. Furthermore, the data indicate that for the participants in this study the legalization of same-sex marriage may be a necessary condition for some aspects of their relationships, but it in itself is not sufficient.

Contrastingly, participants cited challenges arising from routine activities, e.g., conversations at work regarding parenthood, family, interactions with medical providers, insurance representatives, and members of the judiciary system, all served as potential stressors and sources of adversity. More specifically, these obstacles presented themselves regardless of legal marital status, demonstrating the existence of unique negative spaces for some lesbian mothers. In many ways, synthesis of the emergent themes from this study paint a clearer picture of the issues prevalent for members of the lesbian community that cannot be supported by contemporary marriage. Researchers have expressed concern regarding changes in marriage since the late 1800s (Smock, 2004). The controversy that surrounds same-sex marriage draws upon many different facets of social order. However, as many of the 
participants noted throughout this study, legal marriage does secure some protections but it is not a panacea. Participant perceptions and descriptions of their own understandings of marriage and what accessibility to the institution translates to daily varied; namely, depending upon location, socio-economic status, race, and age. Moreover, the majority of participants who had access to legal marriage where they resided and had married described a lack of change in terms of parenting, daily living, and their relationships, aside from the legal components. This shift from moving before the law or against the law to with the law is one that is noted in the data as most often referred to as "validation" and/or having their rights "protected" (Ewick \& Silbey, 1998).

As this theme of guardianship emerged and ran throughout the majority of other areas of concern and struggle for the lesbian women in this sample was that of issues surrounding guardianship. The entire reality of this was brought to light by the juxtaposition of varying state policies regarding adoption laws and marriage legislature. As one participant declared outright after being asked what the biggest challenge she currently faces as a lesbian mother, "My biggest problem is that I have no legal rights to my daughter." This sentiment was reiterated, to varying degrees, by 15 of the 21 participants in this study, with some of the women giving worst-case scenarios to demonstrate the severity of the issue, "What happens if we decide to split, hypothetically? I have no legal protection when it comes to custody."

The varied levels of understanding of how to navigate legal loopholes demonstrated the gradient scale of legal consciousness that was present among the 
sample of participants. For the lesbian mothers who had the economical wherewithal to secure living wills, power of attorney, pay for home study visitations that are required with the adoption process, weaving in and out of the laws to their own advantage was an option. As demonstrated by participants, many of them were readily aware of steps that needed to be taken, they simply lacked the financial resources to take them. For example, one mother living in a state that allowed for same-sex marriage but did not have guardianship over her daughter cited financial restraints as being the primary challenge to filing for adoption:

We keep bringing up that we need to do the adoption. But that's a lot of money. And, like, the home study, and there's jus, it's a lot of lawyers, and it's a lot of money, and we just don't have that money right now.

The issues surrounding guardianship clearly went beyond the adoption process, and in some cases extended into the realm of insurance plans, daycare, hospital visits, and doctor's appointments. In other words, it became apparent that these issues influence daily living for the majority of these lesbian mothers, irrespective of their marital status.

Additionally, some participants found their selected timing of entering into the institution of marriage or in some cases a civil union or domestic partnership working against them over time in terms of guardianship and legal adoption. One participant living in Delaware who had entered a civil union with her partner before same-sex marriage was an option realized even though civil unions became legal marriages in the eyes of the law this did not extend itself to adoptive laws. Heightened awareness 
of legal formalities and unwritten social laws are a part of life for this sample of lesbian mothers.

Furthermore, some of the challenges faced by lesbian mothers in this sample pertained to fundamental aspects of family dynamics. For example, interacting with other family members who are not familiar with same sex couples or aware of the arduous processes that transpired to create a family, as one participant noted, "People forget that Tom isn't biologically tied to me, you know, my dad has slipped and said he has my hair. Which is the outcome we wanted, but still it's hard sometimes." Perhaps most importantly, participants noted that they needed to seek out extraneous protections in a variety of different ways to allow them some of the same legal buffers as marriage. As previously mentioned, many of the participants lacked the financial resources necessary to obtain legal protections individually in an effort to approximate the benefits of legal marriage.

Consequently, this recognition that participation in the institution of marriage being insufficient in terms of both providing equality and assuaging some of the issues surrounding guardianship was met with the understanding that there are more salient issues for members of the LGBTQ community. When asked whether or not the continued push for obtaining same-sex marriage rights should be first priority for the LGBTQ movement and community, a resounding 17 participants agreed that albeit important, it is not the most salient contemporary issue within the community. This finding was unexpected by the researcher and the responses regarding which matters are of primary interest varied but tended to intersect issues of quality of life. As 
participants described, extending rights and protections that would impact more than just the portion of the LGBTQ community that wishes to participate in legal marriage. This level of legal consciousness transcended just their own level of awareness, but an acknowledgement that marriage is in fact, something that is attainment. The achievement of marriage is one that it is predicated upon other factors aside from commitment, and is not something that the entire population has access to; coincidentally, the same is true within the LGBTQ community (Cherlin, 2004). Some participants quite plainly stated that they did not feel obtaining equal access to marriage would in any way help offset other social inequities faced by marginalized LGBTQ individuals and families, for example, on participate stated, “I don't think that same sex marriage is the vehicle to eliminate hate." While other participants cited grave examples of friends lost to violence and/or harassment against LGBTQ, as one participant noted, "There are far more important things. You know, there are people who just aren't surviving day to day." A number of the participants referenced hate crime and anti-discrimination legislature, as stated by a participant from Pennsylvania, "We're all moving in the right direction, um, but, I, I really feel strong, really about having the anti-discrimination laws in effect, because I think that can do more damage than not." This quotation draws upon Bogenschneider's (2006) acknowledgement that the policies we lack are more telling than those we choose to uphold as a society. More specifically, that it is a reflection of larger issues undermining the fight for equality, and that no matter how many or our current policies we amend we are still 
missing fundamental protections for entire groups of marginalized people in our society.

Speaking most generally, the descriptions and experiences of the 21 lesbian women interviewed for this study reflected changing definitions of family. It is quite evident that discourse surrounding what constitutes a family, and how this conversation changes when referencing how family is understood within their own homes, publically, and legally impacts these lesbian mothers and their families daily. Participants offered specific examples as to when and under what conditions they felt most comfortable with the idea of marriage as it became legalized in their state of residence and when access to marriage proved to be supportive and when it proved to be detrimental. Other participants living in parts of the country that do not grant or recognize same-sex marriages spoke of a disconnect between their expectations of marriage and commitment, their experiences with inequality, and the separate and unique challenges faced by them as lesbian mothers. For some participants, the symbolic weight carried by marriage was lighter and less traditional, for others it was rooted heavily in history and ideals and their goal was to approximate the legally binding unions of the majority of the population.

Understandably, many of the participants spoke from a place of frustration and disappointment resulting from a variety of different experiences with injustice on social and legal levels. Lesbian mothers in this study who wanted to be able to parent publically and openly were cautious and always aware of difficulties they may face when engaging with public institutions (e.g., school system and medical 
professionals). Collecting these narratives from participants ended up being more difficult than originally anticipated. As previously noted, geographic limitations prevented the researcher from traveling to conduct 4 of the interviews and they were conducted via internet/Skype chat. While this mode of data collection proved itself to be efficient, these 4 interviews lacked the level of intimacy of the remaining interviews. Furthermore, throughout the recruitment and research process participants were reassured of their identities remaining confidential and anonymous. However, on multiple occasions participants would state they wished for certain experiences or descriptions to remain off the record. One participant, currently employed within the policy arena at a state level, requested that heightened efforts be made to maintain her anonymity. As a result, these data are rich from narratives that were cleared to be disseminated, but will be published without some of the detailed episodic experiences resulting from factors surrounding marriage equality. With that said, the researcher remains humbled by the trust established between herself and the participants during the interview process, and feels privileged to have heard their stories.

During the recruitment process, the state of Delaware legalized same-sex marriage, which impacted 6 of the participants in this study directly. This legal shift during the study proved to be advantageous, as it demonstrated in real time the effects of policy shifts for the participants involved. More specifically, this particular cohort within the sample of lesbian mothers experienced firsthand a shift in marital equality within a specific social, historical, cultural, and political context (Elder, 1989; Hareven, 1987). 
Notably, although not a primary goal of this research endeavor, the vernacular used by the participants in this study was recorded throughout the data collection process. Stark variations exist within this sample of lesbian mothers in terms of what vocabulary they use in reference to themselves, one another, and their relationships. For example, a portion of the sample purposefully avoided terms associated with traditional marriage (e.g., wife and spouse) and opted instead for partner, mate, and lover. Contrastingly, a number of participants felt that the word "partner" felt cold and reminiscent of a business transaction. Similarly, those who did employ terminology typically associated with traditional marriage cited that it should come with marriage equality and that using such vernacular reified their participation in a domain where they were once not allowed to enter. Lastly, four of the participants in this study specifically stated that they interchanged the vocabulary they used depending upon their surroundings and their perception of how use of the word "wife" would be received in certain public arenas. The language used by participants throughout this study once again hones in on the subtle, nuanced differences between heterosexual couples and lesbian couples within the United States.

\section{Lesbian Motherhood}

When this study was first conceptualized, the researcher operated from the standpoint that access to marriage would alleviate the majority of the legal woes entertained by this sample of lesbian women. Access to marriage equality, then, was viewed as the apparatus via which lesbian family life would begin to free itself of daily struggles associated with the previous lack of accessibility. At the outset of this 
study, this understanding of moving with the law and legal equality was supported by existing literature as well as by proponents of same-sex marriage (Lewis \& Gossett, 2008). However, as themes emerged from participant descriptions of marriage and articulation of experiences as lesbian mothers progressed, it became apparent that there was a need to reconsider the extent of the benefits of marriage equality. Namely, the identification of guardianship issues as most salient, the need for protections via hate crime laws and anti-discrimination legislature, and the premeditated nature of parenthood for the majority of the lesbian mothers in this sample prompted the researcher to experience a cognitive shift. When viewed separately, these concerns appear independent of one another. However, the narratives of this sample of lesbian women demonstrate that the intersection of these issues creates a unique vantage point for mothering. In its truest representation, lesbian motherhood is one that is very complicated in its existence within contemporary American culture. Historically, lesbian motherhood was regarded as an oxymoron (Hexembourg, 1999). Lesbian mothers traverse varying pathways to parenthood (e.g., in vitro fertilization, adoption, sperm donation), each of which come with a number of legal hurdles. In this regard, lesbian mothers, gay fathers, and infertile heterosexual couples or those choosing to adopt share a common trajectory, although the pathway itself is inherently different. This point was reiterated by a number of participants, and as one lesbian mother stated:

When we went through fertility treatments, I wrote my name on all the lines for the father. I know this doesn't help anything, but we wanted to leave a 
paper trail showing our intention. But would that actually mean anything? No, it wouldn't.

Something as routine as filling out paperwork in a medical office can prove to be a stressful and frustrating experience for same-sex couples, whereas for heterosexual couples it is less likely to be problematic as the paperwork and formalities were designed for them.

Similarly, the relative importance of social and governmental support for mothers cannot be understated. As articulated by the participants themselves, the majority of the population, existing within dominant cultural ideologies, simply does not understand the daily life experiences of lesbian motherhood. When these experiences were compounded by the intersection of race and ethnicity, as described by 4 of the women in this study, awareness of minority status was further augmented and descriptions included marginalization on multiple fronts. Therefore, a single participant could report numerous experiences with discrimination in terms of access to legal rights, access to legal protections, and access in some cases, to their own children within public and private settings. Moreover, within this sample there was a range of discriminatory experiences as they pertained to identification as a lesbian in conjunction with families themselves being in transition. With this finding comes the realization of the importance of standpoint for each participant. The participants in this study are situated within multiple levels of marginalization within society, across sex, sexuality, and race. Within this sample, narratives pertaining to existing within and outside of the institution of marriage ranged significantly but the commonality of 
themes across experiences suggests that there is direct need for changes in the way we write family policy in the United States. Undoubtedly, the definitions of marriage and family fluctuate, and continue to vary depending upon one's viewpoint. However, the nature and purpose of social policy in the United States is to support and govern its citizens (Lewis \& Gossett, 2008). Contrastingly, the participants in this study have demonstrated that we lack inclusive policies that are able to support these expanding definitions of family. Furthermore, if extending the right to marry to all citizens does not provide necessary and sufficient supports for this sample of lesbian mothers then researchers, professionals, and policymakers are beckoned to reconceptualize family policy beyond the traditional heteronormative parameters.

\section{Limitations and Future Research}

There are a number of limitations pertaining to this research study including the potential for researcher bias, limited generalizability of the qualitative findings, and the homogeneity of the sample itself. The aforementioned limitations could plausibly be curtailed and/or circumvented in future studies exploring same-sex marriage policy and lesbian family life.

The first evident restriction of this research study was the potential for researcher bias. Efforts to limit researcher bias were made via the maintenance of a reflective journal and field notes throughout the research process. Furthermore, the researcher openly acknowledged the influence of their own standpoint and experiences to each participant at the outset of the interview sessions. Moreover, reflexivity was used as a checkpoint whenever applicable. 
Secondly, extending the findings to other populations, albeit not a goal of this particular study, does serve as a limitation. Generally speaking, the primary limitation of the majority of qualitative research is that the findings are not generalizable beyond the study. However, generalizing the findings from this study to other individuals was not the intent of this endeavor. The interview data from each individual in this sample present a unique and rich narrative that can help deepen our understanding of their experiences. The researcher was both humbled and inspired by the specific contributions made by each participant and the exclusive vantage point they shared.

Lastly, the sample was relatively homogenous in terms of socio-economic status, race and ethnicity, and education. Despite reporting differences in financial resources available to file for necessary legal protections, home visitation for adoption procedures, and celebratory ceremonies, it is plausible that this sample did not represent the full gradient scale of socio-economic statuses. All of the participants in this study reported that they were middle to upper-middle class. The majority of the participants were Caucasian, with 17 of the 21 identifying as such; three participants identifying as African-American, and 1 participant identifying as Native American. Furthermore, all of the women in the sample group were born in the United States. Lastly, in terms of education the sample was a relatively highly educated group with 4 participants holding Doctorate level degrees, three having Master's degrees, 10 having obtained Bachelor's degrees, and 4 participants having achieved high school diplomas. In this regard, it is plausible that the represented group was more informed regarding 
their own legal rights and boundaries as a result of their educational levels. It may behoove future researchers to sample groups that are underrepresented in this sample.

Furthermore, it would be advantageous for future research endeavors to include data and information from a number of sources pertaining to experiences with same-sex marriage equality. The experiences of the lesbian women in this sample are paramount for this research study, and carry weight in other arenas as well, but do not necessarily convey a complete understanding of the social phenomenon being explored. Originally, the intent of this study was to explore the influence of marriage accessibility, perceptions of marriage, and discourse surrounding parenthood for a sample of lesbian mothers. However, as the study progressed it became evident that more prominently challenges surrounding guardianship resonated with the participants.

Additionally, future studies would benefit from including the perspectives of the children as well as the parents within this research paradigm. In this particular case, most of the children within these lesbian families were too young to engage in conversations surrounding marriage and family life. However, the prospect of longitudinal research is present with the consent of participants and family members. As this study was the initial step in exploring this social phenomenon from the vantage point of lesbian mothers from different locations in the United States.

Moreover, future research endeavors in this domain would benefit from a longitudinal design. In line with the life course perspective, this particular study was carried out with the sample of lesbian women over the span of 9 months, within a 
specific social, cultural, political, and historical time frame (Edler,1998; Hareven, 1987). While a number of the participants were contacted for follow up clarification, the study was not longitudinal in design. Additionally, adapting this research paradigm to gay fathers in varying parts of the United States would benefit the LGBTQ community and help illuminate important shifts in perceptions and perhaps bring about different concerns for gay fathers as opposed to lesbian mothers.

Further exploration of the issues surrounding guardianship for lesbian mothers is warranted by the findings of this study. While the results cannot be generalized, the thematic progression through the research process illustrated a need for further examination and a deeper understanding. Conclusively, additional research is necessary to further our understanding of the social phenomenon that changing samesex marriage legislature presents to lesbian mothers and families. The present study provides the groundwork for future investigation to expand understanding of varying perceptions and experiences with marriage policy. Insomuch as this understanding could aid and facilitate the restructure and reframing of social family policy, marriage legislature, and adoption processes that impact lesbian family life. Moreover, future research exploring the experiences of cohabiting heterosexual couples with children and guardianship laws would aid in deepening our understanding of where our support systems lack for multiple groups of people.

\section{Implications}

Generally, qualitative research exploring social phenomena of this nature is relegated to the realm of academia. Furthermore, discourse surrounding the topic of 
same-sex marriage as it directly pertains to members of the LGBTQ community is mostly understood and accepted within the parameters of the community itself. However, a need exists for findings to be disseminated on multiple levels. First and foremost, it is a testament to the lesbian women who volunteered their time, energy, and histories to this research endeavor that work such as this can be conducted. Therefore, cycling the results back to participants and LGBTQ community level organizations is imperative to help spread the word about concerns raised, challenges, and tap potential resources within the community. This feedback loop invariably permeates other facets individual and family life, and the goal is to involve the broader, general community as well to help effectuate social change in the communities where lesbian mothers are raising their children.

Several findings from this research study directly pertain to social policy in the United States. Primarily, the expressed concern and frustration regarding guardianship issues for the lesbian mothers in this sample demonstrate a lack of support by policy. Numerous interactions with medical professionals, members of the education system, and other regulatory institutions highlight the experiences of these women on a daily basis. The understanding that same-sex marriage being legalized will translate to alleviation of a significant amount of the struggles faced by lesbian mothers has been discounted by the experiences of the sample within the present study. Implications reach beyond community level advocacy and extend themselves to the realm of social policy. The institution of marriage is one that has been contested for centuries (Smock, 2004). However, the stories of the lesbian women in this 
sample provide impetus for looking beyond marriage to help support lesbian families and their children. Cherlin (2004) contends that the deinstitutionalization of marriage is reflected by the dilution and abatement of social norms. Perhaps it is more so that our society is moving in multiple directions that cannot all be supported by our traditional norms, and that the proliferation of a number of family structures indicates a need for a shift in our understanding of what is 'traditional.' While this prospect may be discouraged and marginalized by some policymakers, it warrants further exploration, as maintenance of social order via governmental institutions within the United States can only subsist if the supports afforded by the institutions themselves are relevant.

The general sentiment of participants who had access to legal marriage and had pursued the license within their relationship was that the state by state variations created unprecedented difficulties that were, by and large, discriminatory. This finding can be interpreted as necessitation for same-sex marriage to be accessible on a federal level. Furthermore, engendering research that can influence policymaking is critical to social change on local, state, and federal levels (Bogenschneider, 2006). This project provides a fundamental piece to deepening our understanding of the puzzle surrounding same-sex marriage policy the United States in that it, by design, disseminates information to individuals in varying societal positions. More specifically, as lesbian mothers, the participants of this study maintain positions both within and outside of the LGBTQ community. All too often, policymakers are unfamiliar with family dynamics and the unique struggles of daily life for families and 
individuals (Bogenschneider, 2006). This lack of familiarity contributes to an inability to accurately ascertain what kind of social policy would truly support our diverse population.

\section{Contributions of this Study}

In summation, the narratives of the lesbian women in this study provide a unique vantage point into the range of experiences with social policies in varying parts of the United States. As conceptualized and framed by the aforementioned emergent themes, it is readily apparent that there was some participant overlap. For many of the participants, it was very difficult to disentangle societal expectations and norms from their understanding of marriage as an institution that either proved supportive or detrimental.

In this way, on a micro level, the lesbian mothers that participated in this study were provided an opportunity to reflect and express their thoughts, opinions, understandings, misconceptions, and expectations in a receptive and safe environment. For many, this was an unprecedented opportunity, as stated by the majority of participants.

Additionally, on a more macro-level, this research in conjunction with other studies exploring the influence of social policy on LGBTQ family structures in the United States presents a need for attention from both the academic community as well as the general public. However, the same argument can be made for this line of research necessitating work of a similar nature on a global level. The United States 
presents a useful case study when taking into account the levels of acceptance via social policy in varying parts of the world.

However, perhaps more importantly, the results of this study will be divulged to participants and within the lesbian community, and spread on social media. By exploring previously unchartered territory, this research will add to the growing body of literature focusing on lesbian families and shed light into some of the nuanced aspects of family life, or negative spaces, surrounding marriage ideals and goals (Daly, 2003); in hopes of shifting perceptions of lesbian family life and supporting marriage equality for all.

Similarly, this study redirects the importance of recognizing the social influences on the family, which to date has predominantly focused on heterosexual family structures (D’Onforio \& Lahey, 2010). The interplay between biological and social factors has been of longstanding interest for family scientists. However, the biosocial influences on lesbian families warrant studies independent of traditional heteronormative guidelines. On a fundamental level, this study has demonstrated that a number of the social concerns faced by lesbian mothers are potentially different from those of heterosexual mothers. Furthermore, that should these differences be expressed, that they are inherent differences as illustrated by the varying positions held in society by each of these groups of mothers (Harding, 1987). In this way, the social construction of marriage for the lesbian mothers in this study was often rooted in traditional understandings of marriage, but the transition itself differed significantly as a result of social influences (Byrd, 2009). 


\section{CONCLUSION}

Through analysis of narratives, examination of legal consciousness, and synthesis of themes this research illustrated the unique issues faced by lesbian mothers in the United States. The results of this study also convey the need for proponents of same-sex marriage legislation to recognize that access to marriage is not a panacea. The understanding that inclusive marriage policy cannot be truly inclusive of changing family structures is one that is clearly supported by the data. The unique experiences of the 21 participants in this study delineate the need for a more direct relationship between policy and families.

The data obtained through this research is situated within a specific cultural context, and while this historical moment will never be duplicated, it will serve to educate future cohorts of lesbian mothers about adversity faced by participants raising children in this time period. The ambivalence towards marriage expressed by some of the lesbian mothers in this study presents a unique social issue for policymakers; as all of these women want to approximate the rights afforded to heterosexual married couples, but they do not all necessarily want to marry. Continuing this point, to what extent the participants perceived interference from the government in their lives as similar or different to their heterosexual counterparts varied significantly. Once again this consistency illuminates the insufficient family policy at work in the United States.

Additionally, the narratives provided by the participants in this study contributed to furthering our understanding of how legislation influences the daily lives of marginalized populations in different ways. The data also provided a sense of 
the central issues these lesbian mothers are facing, including but not limited to, issues surrounding guardianship rights for their children. The women in this study shared their experiences and articulated their perspectives, and in many cases they felt as if they were being treated as second-class citizens in terms of familial support from the government in the form of inclusive policies. Consequently, it is the perceptions of marriage legislation that resulted in the spectrum of responses and justifications in terms of the institution of marriage and its place in their lives.

Lastly, it is important to note that the feminist standpoint taken by the researcher predicates that one of the primary goals of this project was investigating women's perceptions through their own voices (Harding, 1987). As someone in a committed lesbian relationship, at the outset of this study I was a stalwart proponent of same-sex marriage. While I did not view it as the only issue the GLBTQ community should be attending to, I did regard it as one that was essential to obtaining equal rights. However, through interacting with participants and learning throughout the research process, my own perspective has shifted. The connections I formed with the lesbian women in this study are rooted in empathy and understanding. More specifically, sharing experiences and perspectives has resulted in the development of shared meaning. In many ways, my understanding of marriage has become less about achieving legal equality as a catalyst for social equality, and more so about finding a way to provide the supports that many of the lesbian mothers in our country need on a daily basis. I hope that participating in this research has empowered the lesbian women I interviewed, and demonstrated to them that their lives are of interest and that 
their families are important. In many ways, by providing a voice for them I have inadvertently provided one for myself as well. 


\section{REFERENCES}

Adams \& Phillips (2006). Experiences of two-spirit lesbian and gay Native Americans: An argument for standpoint theory in identity research. Identity: an International Journal of Theory and Research, 6(3), 273-291.

Agar, M. (1986). Speaking of Ethnography. Beverly Hills: Sage.

Akers, R.L. (1985). A social learning perspective on deviant behavior. $3^{\text {rd }}$ ed. Belmont: Wadsworth.

Allen, K. R. \& Demo, D.H. (1995). The families of lesbians and gay men: a new frontier in family research. Journal of Marriage and Family, 57(1), 111-127.

Amato, P. R. \& Kane, J.B. (2011). Life course pathways and the psychosocial adjustment of young adult women. Journal of Marriage and Family, 73, 279 295.

Andrews, K. (2001). Social movements and policy implementation: the Mississippi civil rights movement and the war on poverty, 1965-1971. American Sociological Review, 66, 71-95.

Baumeister R.F. \& Vohs, K.D. (2004). Sexual economics of sex as female resource for social exchange in heterosexual interactions. Social Psychology, 8(4), 339-363.

Bengston, V.L. \& Allen, K. (1993). The life course perspective applied to families over time. Sourcebook of Family Theories and Methods. Springer: Blacksburg.

Bengtson, V. L. (2001). Beyond the nuclear family: The increasing importance of multigenerational bonds. Journal of Marriage and Family, 63(1), 1-16.

Bernal, J.D. (1967). The origin of life. World: Cleveland. 
Biblarz, T. J., \& Stacey, J. (2010). How does the gender of parents matter? Journal of Marriage and Family, 72(1), 3-22.

Bogenschneider, K. (2006). Family policy matters: How policymaking affects families and what professionals can do. $2^{\text {nd }}$ ed. Routledge.

Brumbaugh, S.M., Sanchez, L.A., Nock, S.L., \& Wright, J.D. (2008). Attitudes towards gay marriage in states undergoing marriage law transformation. Journal of Marriage and Family, 70(2), 345-359.

Bumpass, L., \& Hsien-Hen, L. (2000). Trends in cohabitation and implications for children's family contexts in the United States. Population Studies: A Journal of Demography, 54(1), 29-41.

Brewer, P.R., \& Wilcox, C. (2005). Same-sex marriage and civil unions. Public Opinion Quarterly, 69(4), 599-616.

Brown, G. (2012). Homonormativity: a metropolitan concept that denigrates “ordinary” gay lives. Journal of Homosexuality, 59(7), 1065-1072.

Brown, M. J., \& Henriquez, E. (2011). Support for Gay and Lesbian civil rights: Development and examination of a new scale. Journal of Homosexuality, $58(4), 462-475$.

Burn, S.M. (2005). Women across cultures: a global perspective. 2e. New York: McGraw-Hill.

Burstein, P. (1991). Legal mobilization as a social movement tactic. American Journal of Sociology, 96, 1201-1225. 
Burstein, P. \& Linton, A. (2002). The impact of political parties, interest groups, and social movement organizations on public policy: Some recent evidence and theoretical concerns. Social Forces, 81, 380-408.

Cahill, C.M. (2004). Same-sex marriage, slippery slope rhetoric, and the politics of disgust: a critical perspective on contemporary family discourse and the incest taboo. Northwestern University Law, 99(4), 1543-1567.

Campbell, D.T. \& Stanley, J.C. (1966). Experimental and quasi-experimental designs for research. Boston: Houghton Mifflin Company.

Card, C. (1996). Against marriage and motherhood. Hypatia, 11(3), 1-23.Clarke, V. (2003). Lesbian and gay marriage: Transofrmation or normalization? Feminism \& Psychology, 13(4), 519-529.

Carrington, C. (1999). No place like home: Relationships and family life among lesbians and gay men. Chicago: University of Chicago Press.

Chambers, D.L. (1996). What if? The legal consequences of marriage and the legal needs of lesbian and gay male couples. Michigan Law Review, 447-491.

Clarke, V. (2003). Lesbian and gay marriage: Transformation or normalisation?. Feminism \& Psychology, 13(4), 519-529.

Clarke, V., Burns, M., \& Burgoyne, C. (2008). 'Who would take whose name?'Accounts of naming practices in same-sex relationships. Journal of Community \& Applied Social Psychology, 18(5), 420-439.

Coontz, S. (1992). The way we never were: American families and the nostaligia trip. New York: Basic Books. 
Coontz, S. (2000). Historical perspectives on family studies. Journal of Marriage and Family, 62(2), 283-297.

Coontz, S. (2005). Marriage: a history. London: Penguin Books Ltd.

Corbin, J., \& Strauss, A. (Eds.). (2008). Basics of qualitative research: Techniques and procedures for developing grounded theory. Washington D.C.: Sage.

Cress, D.M. \& Snow, D.A. (2000). The outcomes of homeless mobilization: the influence of organization, disruption, political mediation, and framing. American Journal of Sociology, 105, 1063-1104.

Creswell, J. W. (2013). Research design: Qualitative, quantitative, and mixed methods Approaches. Thousand Oaks, CA: Sage.

Creswell, J. W., \& Clark, V. L. P. (2007). Designing and conducting mixed methods research. Thousand Oaks, CA: Sage.

Creswell, J. W. \& Miller, D. L. (2000). Determining validity in qualitative inquiry. Theory into Practice, 39(3), 124-131.

Daly, K. (2003). Family theory versus the theories families live by. Journal of Marriage and Family, 65(4), 771-784.

Daly, K. (2007). Qualitative methods for family studies and human development. Thousand Oaks, CA: Sage.

DeFrain, J., \& Asay, S.M. (2007). Strong families around the world: an introduction to the family strengths perspective. Marriage \& Family Review, 4(1/2), 1-10.

Denzin, N. (1978). Sociological methods. New York: McGraw Hill. 
Duggan, L. (2002). The new homonormativity: the sexual politics of neoliberalism. In R. Castronovo \& D.D. Nelson (eds), Materializing democracy: Towards a revitalized cultural politics, 175-194. Durham, NC: Duke University Press.

Edwards, R., Mauthner, M., Mauthner, M., Birch, M., Jessop, J., \& Miller, T. (2002). Ethics in Qualitative Research. Thousand Oaks, CA: Sage.

Egan, P.J. \& Sherrill, K. (2005). Marriage the shifting priorities of a new generation of gays and lesbians. Political Science \& Politics, 2, 229-242.

Elder, G. H. (1998). The life course as developmental theory. Child Development, 69(1), 1-12.

Ellis, S. J., Kitzinger, C., \& Wilkinson, S. (2003). Attitudes towards lesbians and gay men and support for lesbian and gay human rights among psychology students. Journal of homosexuality, 44(1), 121-138.

Ewick, P., \& Silbey, S. S. (1998). The common place of law: Stories from everyday life. Chicago: Chicago University Press.

Fay, (1987). Critical social science: Liberation and its limits. Ithaca, NY: Cornell University Press:

Figure 1. Data analysis spiral. Adapted from "Qualitative inquiry and research design: Choosing among five approaches" (2 ${ }^{\text {nd }}$ ed.), by J.W. Creswell, 2007, p. 151. Copyright 2007 by SAGE Publications.

Flick, U. (2006). Designing qualitative research. Thousand Oaks, CA: Sage.

Freeman, M. \& Vasconcelos, E.F.S. (2010). Critical social theory: Core tenets, inherent issues. In M. Freedman (Ed.), Critical social theory and evaluation 
practice. New directions for evaluation, 127, 7-19.

Galanter, M. (2001). Changing legal consciousness in America: the view from the joke corpus. Cardozo Law Review, 23, 2223-2240.

Gartrell, N., Rodas, C., Deck, A., Peyser, H., \& Banks, A. (2006). The USA national lesbian family study: Interviews with mothers of 10-year-olds. Feminism \& Psychology, 16(2), 175-192.

Gilligan, C. (1982). In a different voice. Boston, MA: Harvard University Press.

Gillies, V. (2005). Meeting parents' needs? Discourses of 'support' and 'inclusion' in family policy. Critical social policy, 25(1), 70-90.

Gillis, J.R. (1999). "A triumph of hope over experience": Change and choice in the history of marriage. International Review of Social History, 44, 47-54.

Giugni, M., McAdam, D., \& Tilly, C. (1999). How social movements matter. Minneapolis, MN: University of Minnesota Press.

Given, L.M. (Ed.). (2008). The Sage encyclopedia of qualitative research methods. Thousand Oaks, CA: Sage.

Glaser, B.G. (1978). Theoretical sensitivity. Sociology Press: Mill Valley.

Glaser, B.G. \& Strauss, A.L. (1967). The discovery of grounded theory: Strategies for qualitative research. Chicago: Aldine.

Goffman, E. (1963). Stigma: Notes on the management of spoiled identity. Englewood Cliffs: Prentice-Hall.

Goldberg, A. E., \& Kuvalanka, K. A. (2012). Marriage (in) equality: The perspectives of adolescents and emerging adults with lesbian, gay, and bisexual parents. 
Journal of Marriage and Family, 74(1), 34-52.

Goodridge v. Department of Public Health, 14 Mass. L. Rep. 591; 2002 Mass. Super. (2003).

Guba, E. G. (1981). Criteria for assessing the trustworthiness of naturalistic inquiries. Educational Resources Infonnation Center Annual Review Paper, 29, 75-91.

Haas, S.M. (2002). Social support as relationship maintenance in gay male couples coping with HIV or AIDS. Journal of Social and Personal Relationships, $19(1), 87-111$.

Haider-Markel, D.P. (2001). Policy diffusion as a geographical expansion of the scope of political conflict: Same-sex marriage bans in the 1990s. State Politics \& Policy Quarterly, 1(1), 5-26.

Harding. S. (1986). The science question in feminism. Ithaca, NY: Cornell University Press.

Harding, S. (1991). Whose Science? Whose Knowledge? Thinking from Women's Lives. Ithaca, NY: Cornell University Press.

Hareven, T.K. (1987). Family history at the crossroads. Journal of Family History, $12(1-3), 9-23$.

Hartsock, N.C.M. (1983). Money, sex, and power: Toward a feminist historical materialism. Boston: Northeastern University Press.

Hartsock, N.C.M. (1999). The feminist standpoint revisited, and other essays. London: Basic Books. 
Henry, R.G., Miller, R.B., \& Giarrusso, R. (2005). Difficulties, disagreements, and disappointments in late-life marriages. International Journal of Aging and Development, 61, 243-264.

Herdt \& Kertzner (2006). I do, but I can't: The impact of marriage denial on the mental health and sexual citizenship of lesbians and gay men in the United States. Sexuality Research and Social Policy Journal of NSRC, 3(1), 33-49.

Hequembourg, A.L., \& Farrell, M.P. (1999). Lesbian motherhood. Gender \& Society, 13(4), 540-557.

Hochschild, J.L. (1996). Facing up to the American dream: Race, class, and the soul of the nation. Princeton University Press.

Homfray, M. (2008). Standpoint, objectivity, and social construction: Reflections from the study of gay and lesbian communities. Sociological Research Online, $13(1), 7$.

Hopkins, J.J., Sorensen, A., \& Taylor, V. (2013). Same-sex couples, families, and marriage: Embracing and resisting heteronormativity. Sociology Compass, $7(2), 97-110$.

Huston, A.C. (1994). Children in poverty: Child development and public policy. Boston, MA: Cambridge University Press.

Jaccard, J. \& Jacoby, J. (2011). Theory construction and model-building skills: a practical guide for social scienteists. Guilford Press.

Jacob, S.A. \& Furgerson, S.P. (2012). Writing interview protocols and conducting interviews: Tips for students new to the field of qualitative research. The 
Qualitative Report, 17(6), 1-10.

Josephson, J. (2005). Citizenship, same-sex marriage, and feminist critiques of marriage. Perspectives on Politics, 3(2), 268-284.

Kinsey, A.C., Poeroy, W.B., \& Martin, C.E. (1948). Sexual behavior in the human male. Bloomington, IN: Indiana University Press.

Kinsey, A.C. (1953). Sexual behavior in the human female. Bloomington, IN: Indiana University Press.

Knox, S. \& Burkard, A. (2009). Qualitative research interviews. Psychotherapy Research, 19(4/5), 20-39.

Koppelman, A. (2004). "The Decline and Fall of the Case against Same-Sex Marriage,"University of St. Thomas Law Journal: Vol. 2: Iss. 1, Article 2. couples. Journal of Social Issues, 49, 127-139.

Krefting, L. (1991). Rigor in qualitative research: the assessment of trustworthiness. The American Journal of Occupational Therapy, 45(1), 214-222.

Kurdek, L.A. (2004). Are gay and lesbian cohabiting couples really different from heterosexual married couples? Journal of Marriage and Family, 66, 880-900.

Lambert, S. (2005). Gay and lesbian families: What we know and where to go from here. The Family Journal, 13, 43-51.

Lanutti, P.J. (2007). For better or worse: Exploring the meanings of same-sex marriage within the lesbian, gay, bisexual, and transgendered community. Journal of Social and Personal Relationships, 22(5), 377-383. 
Lannutti, P.J. (2007a). The influence of same-sex marriage on the understanding of same-sex relationships. Journal of Homosexuality, 53, 135-151.

Lather, P. (1986). Issues of validity in openly ideological research: Between a rock and a soft place. Interchange, 17(4), 63-84.

Lewis, G.B. (2005). Same-sex marriage and the 2004 presidential election. PS: Political Science and Politics, 38(2), 195-199.

Lewis, G.B. \& Gossett, C.W. (2008). Changing public opinion on same-sex marriage: the case of California. Politics \& Policy, 36(1), 4-30.

Lincoln, Y.S. \& Guba, E.G. (1985). Establishing trustworthiness. Naturalistic Inquiry, 289-331.

Loftus, J. (2001). America's liberalization in attitudes toward homosexuality, 19731998. American Sociological Review, 66(5), 762-782.

Mabry, L. (2010). Critical social theory evaluation: Slaying the dragon. In M. Freeman (Ed.), Critical social theory and evaluation practice: New Directions for Evaluation, 127, 83-98.

Manning, W. D., \& Cohen, J. A. (2012). Premarital cohabitation and marital dissolution: An examination of recent marriages. Journal of Marriage and Family, 74(2), 377-387.

McLaren, S. (2009). Sense of belonging to the general and lesbian communities as predictors of depression among lesbians. Journal of Homosexuality, 56, 1-13.

McNamara, P. (2009). Feminist Ethnography Storytelling that Makes a Difference. Qualitative Social Work, 8(2), 161-177. 
Nadin, S. \& Cassell, C. (2006). The use of a research diary as a tool for reflexive practice: Some reflections from management research. Qualitative Research in Accounting \& Management, 3(3), 208-217.

Naples, N.A. (2003). Feminism and method: Ethnography, discourse analysis, and activist research. New York: Routledge.

Olson, L.R., Cadge, W., Harrison, J.T. (2006). Religion and public opinion about same-sex marriage. Social Science Quarterly, 87(2), 340-360.

Ortlipp, M. (2008). Keeping and using reflective journals in the qualitative research process. The Qualitative Report, 13(4), 695-705.

Parsons, T. (1951). TheSocial System. New Yorkand London: The Free Press and Collier Macmillan.

Patterson, C.J. (2000a). Children of lesbian and gay men. Child Development, 63(5), $1025-1042$.

Patterson, C.J. (2000b). Family relationships of lesbians and gay men. Journal of Marriage and the Family, 62, 1052-1069.

Patterson, C.J. (2005). Lesbian and gay parents and their children: Summary of research findings. In: Lesbian and Gay Parenting. American Psychological Association, Washington D.C.: Routledge.

Patterson, C.J. (2009). Children of lesbian and gay parents: Psychology, law, and policy. American Psychologist, 64(8), 727-736.

Patton, M. Q. (2005). Qualitative research. New York, NY: John Wiley \& Sons, Ltd. 
Peplau, L. A., \& Fingerhut, A. W. (2007). The close relationships of lesbians and gay men. Annual Review of Psychology., 58, 405-424.

Perlesz, A., Brown, R., Lindsay J., McNair, R., deVaus, D., \& Pitts, M. (2006). Family in transition: Parents, children, and grandparents in lesbian families give meaning to 'doing family.' Journal of Family Therapy, 28, 175-199.

Polikoff, N. D. (1993). We will get what we ask for: Why legalizing gay and lesbian marriage will not dismantle the legal structure of gender in every marriage. Virginia Law Review, 79, 1535.

Ribar, D. C. (2004). What do social scientists know about the benefits of marriage?: A review of quantitative methodologies (No. 998). IZA Discussion paper series.

Rich, A. (1980). Compulsory heterosexuality and lesbian existence. Signs, 5(4), 631660.

Sandelowski, M. (1986). The problem of rigor in qualitative research. Advances in Nursing Science, 8, 27-37.Schwartz, P., \& Blumstein, P. (1983). American couples: Money, work, sex. New York: William Morrow \& Company.

Schmid, H. (1981). American occupational therapy foundation- qualitative research and occupational therapy. Journal of Occupational Therapy, 35, 105-106.

Shenton, A. K. (2004). Strategies for ensuring trustworthiness in qualitative research projects. Education for information, 22(2), 63-75.

Sherkat, D. E., Powell-Williams, M., Maddox, G., \& De Vries, K. M. (2011). Religion, politics, and support for same-sex marriage in the United States, 1988-2008. Social Science Research, 40(1), 167-180. 
Siegenthaler, A.L. \& Bigner, J.J. (2008). The value of children to lesbian and nonlesbian mothers. Journal of Homosexuality, 39(2), 73-91.

Smart, C. \& Shipman, B. (2004). Visions in monochrome: Families, marriage, and the individualization thesis. The British Journal of Sociology, 55(4), 491-509.

Somera, W. (1999). Baehr v. Lewin-Miike. Journal of Gender, Social Policy, and the Law, 8, 227-230.

Soule, S.A. (2004). Going to the chapel? Same-sex marriage bans in the United States, 1973-2000. Social Problems, 51(4), 453-477.

Stoddard, T.B. (1997). Why gay people should seek the right to marry, in Mark Blasius and Shane Phelan (eds), We are everywhere: a historical sourcebook of gay and lesbian politics, 753-757. New York: Routledge.

Strauss, A. (1987). Qualitative analysis for social scientists. Cambridge, UK: Cambridge University Press.

Strauss, A., \& Corbin, J. (1998). Basics of qualitative research: Grounded theory procedures and techniques. Thousand Oaks: Sage.

Sweeney, M.M. (2002). Two decades of family change: the shifting economic foundations of marriage. American Sociological Review, 67(1), 132-147.

Turner, D.W. III. (2010). Qualitative interview design: a practical guide for novice investigators. The Qualitative Report, 15(3), 754-760.

U.S. Census Bureau. (2010). Estimates of same-sex couples. Retrieved September $28^{\text {th }}, 2012$, from www.census.gov. 
Weissbourd, B. (1987). Design, staffing, and funding of family support programs. In Kagan, S., Powell, D., Weissbourd, B., \& Zigler, E. (Eds.), (1987). America's Family Support Programs. (pp. 245-268) New Haven: Yale University Press.

Whitbourne, S. K., \& Powers, C. B. (1994). Older women's constructs of their lives: A quantitative and qualitative exploration. The International Journal of Aging and Human Development, 38(4), 293-306.

White, J.M. \& Klein, D.M. (2002). Family theories: Second edition. Thousand Oaks, CA: Sage Publications. 


\section{Appendix A}

\section{ORIGINAL SEMI-STRUCTURED INTERVIEW PROTOCOL}

Hello, thank you for taking the time to talk with me today. My name is Nikki DiGregorio and I am gathering data with the goal of exploring the lives of lesbian families and their relationship to same-sex marriage legislation. I want to know what it means for you, your family, your relationship, what you think it could mean in the future, and what your hopes are regarding family. I would like to begin by telling you a little about myself. I am open about my sexuality, and have been an out lesbian since I was 17 years old. My parents were initially very upset with me, and my father asked me to move out of the house. It has taken many years to reconcile some of that anger, on both ends, and even to this day my parents refuse to acknowledge or legitimate my relationship with my partner. I feel that marriage equality plays a role in this, in a variety of ways. As I became more involved in the local gay and lesbian community, I learned there are differing experiences and opinions to be heard regarding social policy and family life. I want to learn more about the day to day parts of your life and try to gain a deeper understanding of what that means for same-sex marriage legislature.

1) Can you tell me a little bit about yourself?

\section{A. Demographics, job, family history}

2) How long have you been with your partner?

3) How old is your child/are your children?

4) How long have you lived where you currently reside? Do you like it here? Why/Why not?

5) What does marriage mean to you?

A. What do you think of when you hear the word?

6) Have you and your partner previously discussed marriage? To what extent? 
A. If you have, has your stance changed on this issue over time?

Why/Why not?

7) Do you think state-level laws influence your day-to-day activities? If so, how?

8) What are your thoughts regarding the changes in same-sex marriage legislature in your state of residence? OR

9) Please tell me your thoughts regarding the lack of marriage equality in your state of residence?

10) Do you perceive differences between cohabiting and being married? Why/Why not? To what extent/on what level(s)?

11) Have you and your partner ever hosted a commitment ceremony? Why/why not?

12) Is marriage symbolic to you? Why/why not?

13) Do you feel that obtaining marriage equality is important to the GLBTQ movement? Why/why not?

14) What do you see as some of the benefits/challenges of obtaining marriage equality?

15) Has your experience as a parent been influenced by your marriage status? Please give examples if you feel comfortable.

16) What, do you feel, are the biggest challenges you face as a lesbian mother? (If applicable) Do you think these would be different if you were married to your partner? How so?

17) Has your relationship changed, from your perspective, with the shifts in 
marriage equality policy?

18) If applicable: Would you seek marriage if it became available to you? Why/why not?

19) Would you like to add anything? Do you know of other lesbian couples that would like to participate? Thank you for your time and participation, I believe your input will be valuable to this research in many ways.

20) Are you comfortable with being contacted a month from now to confirm that I am reflecting your experiences accurately?

Probes:

Household help

Cooking

Childcare

Surprises/concerns

Expectations

Residency

Occupations

Social support

Wills

Power of Attorney

Commitment ceremony 


\section{Appendix B}

\section{REFLECTIVE JOURNAL TEMPLATE}

\section{Date:}

\section{Location:}

\section{Timeframe:}

\section{Sensitizing Concepts:}

Benefits/Challenges to obtaining marriage

Relationship status

Parenting

Social Support

Hopes/Future Plans

Daily Life

Connections to Policy

Changes in Opinion

Ideas of Validation/Legitimating

Socio-political-historical References

Legal Consciousness

Subjective Reflections: 
Appendix C

\section{INFORMED CONSENT AGREEMENT FOR PARTICIPANTS}

Title of study: Same-sex marriage policies and lesbian family life

Principal investigator: Nikki DiGregorio, M.A.

Institute: Department of Human Development and Family Studies, University of Delaware

\section{Introduction:}

I am Nikki DiGregorio from the Department of Human Development and Family Studies and researching same-sex marriage laws and lesbian families with children. I am exploring how equal access to marriage influences family processes among lesbian couples with children, I invite you to join this research study.

\section{Purpose of this research study}

This study that will build upon existing research by investigating the relationship between marriage equality and its impact on parenting and committed, monogamous relationships for lesbian women. Specifically, this study will explore how marriage equality, or the lack there of, affects the daily lives of lesbian mothers and their children.

\section{Procedures}

In this study you will be asked questions about your relationship, parenting, as well as your thoughts and hopes regarding marriage and the institution of marriage itself. It is estimated that the interview will take approximately an hour of your time.

\section{Possible risks or benefits}

There are no perceived risks to this study. A direct benefit of this study is having the opportunity to share your experiences and have your voice heard. The results of this study will contribute to academic literature in the growing body of research exploring lesbian families.

\section{Right of refusal to participate and withdrawal}


You are free to choose to participate in the study. You may refuse to participate without any repercussions. You may also withdraw any time from the study, and you may also opt to not be contacted in the future. You may refuse to answer some or all of the questions asked.

\section{Confidentiality}

The information provided by you will remain confidential. Nobody except the principal investigator will have an access to it. Your name and identity will also not be disclosed at any time. The data collected from the interviews may be published in an academic journal and elsewhere without giving your name or disclosing your identity.

\section{Contact Information:}

If you have any further questions you may contact the Principal Investigator:

Nikki DiGregorio

Department of Human Development and Family Studies

University of Delaware

NikkiD@udel.edu

(610)731-1492

\section{AUTHORIZATION}

I have read and understand this consent form, and I volunteer to participate in this research study. I understand that I will receive a copy of this form. I voluntarily choose to participate, but I understand that my consent does not take away from my ability to stop participating at any point in time.

Participant's Name:

Date:

Participant's Signature :

Date:

Principal Investigator's Signature:

Date: 


\section{Appendix D}

\section{PERMISSION TO USE COPYRIGHTED FIGURE}

\section{Google apps

\section{RE: Permissions inquiry}

permissions (US) < permissions@sagepub.com>

Tue, Feb 25, 2014 at 2:10

To: Nikki DiGregorio<nikkid@udel.edu>

Dear Nikki,

Thank you for your request. You can consider this email as permission to reprint the material as detailed below in your upcoming dissertation. Please note that this permission does not cover any $3^{\text {rd }}$ party material that may be found within the work. We do ask that you properly credit the original source, SAGE

Publications. Please contact us for any further usage of the material.

Best regards,

Michelle Binur

From: Nikki DiGregorio [mailto:nikkid@udel.edu]

Sent: Tuesday, February 25, 2014 9:50 AM

To: permissions (US)

Subject: Re: Permissions inquiry

Hi Michelle,

Thank you for the prompt response. I am referring to the "data analysis spiral" on page 151 of the 2007 edition.

Thank you again for your help,

Nikki

On Tue, Feb 25, 2014 at 12:46 PM, permissions (US) 
<permissions@sagepub.com> wrote:

Dear Nikki,

Thank you for your request. Could you tell us which figure and page number the material you wish to use appears in? Once we have that information, we can further review your request.

Best regards,

Michelle Binur

Rights Assistant

SAGE Publications Inc.

Michelle.Binur@sagepub.com

www.sagepub.com

Los Angeles | London | New Delhi

Singapore | Washington DC

The natural home for authors, editors \& societies

From: Nikki DiGregorio [mailto:nikkid@udel.edu]

Sent: Tuesday, February 25, 2014 8:31 AM

To: permissions (US)

Subject: Permissions inquiry

Hello,

I am writing to inquire as to how I would go about obtaining consent to use a figure from: Creswell, J.W. (2007). Qualitative inquiry and research design: Choosing among five approaches ( 2 nd ed.). Thousand Oaks,

CA: Sage.

I am writing my dissertation and am not sure if citing the figure in text and references is sufficient.

Any help would be greatly appreciated, Thank you,

Nikki DiGregorio 


\section{Appendix E}

\section{UNIVERSITY OF DELAWARE IRB APPROVAL LETTER}

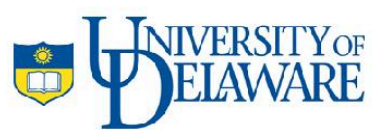

DATE

TO:

FROM:

STUDY TITLE:

SUBMISSION TYPE

ACTION:

APPROVAL DATE:

EXPIRATION DATE:

REVIEW TYPE:

\author{
Research Office
}

University of Delaware

Ph: 302/831-2136

Fax: 302/831-2828

REVIEW CATEGORY:

July 17,2013

Nikki DiGregorio

University of Delaware IRB

[474369-3] Same-sex marriage policies and lesbian family life

Amendment/Modification

APPROVED

July 17,2013

June 10, 2014

Expedited Review

Thank you for your submission of Amendment/Modification materials for this research study. The University of Delaware IRB has APPROVED your submission. This approval is based on an appropriate risk/benefit ratio and a study design wherein the risks have been minimized. All research must be conducted in accordance with this approved submission.

This submission has received Expedited Review based on the applicable federal regulation.

Please remember that informed consent is a process beginning with a description of the study and insurance of participant understanding followed by a signed consent form. Informed consent must continue throughout the study via a dialogue between the researcher and research participant. Federal regulations require each participant receive a copy of the signed consent document.

Please note that any revision to previously approved materials must be approved by this office prior to initiation. Please use the appropriate revision forms for this procedure.

All SERIOUS and UNEXPECTED adverse events must be reported to this office. Please use the appropriate adverse event forms for this procedure. All sponsor reporting requirements should also be followed.

Please report all NON-COMPLIANCE issues or COMPLAINTS regarding this study to this office.

Please note that all research records must be retained for a minimum of three years.

Based on the risks, this project requires Continuing Review by this office on an annual basis. Please use the appropriate renewal forms for this procedure. 